\title{
فاعلية بعض الأنشطة التربوية المقترحة في تنمية مفهوم الاختلاف والتعدية الثقافية وقبول الاخر لاى الاطفال
}

\section{إعداد}

د/ رشا اسماعيل خليل '

ملخص البحث:

تكمن مشكلة البحث في تتاول فكرة تنمية مبدأ تقبل الاختلاف مع الاخر و تعدد الثقافات خصوصا بعد التطورات التكنولوجية التي ساهمت في تغير القيم المجتمعية، فكان من الضروري العمل على تنشئة الطفل في مرحلة الطفولة المبكرة على كيفية تقبل هذه الاختلاف و التعدد التقافي ،وتمثل الانشطة التربوية جزء هام في الروضة حيث تقدم هذه الانشطة للطفل في الروضة من أجل ممارستها ثم التحدث عنها بلغته ويدرب علي التعبير أكثر من مرة ثم يراجع نفسه لتعديل التعبير لكي يكون أكثر دقة لذا دعت الحاجة القيام بهذا البحث وهو اقتر اح بعض الأنشطة التربوية التي تساعد في تنمية مفهوم تقبل الاخر و الاختلاف و تعدد الثقافات ويجيب البحث على التساؤل الرئيسي وهو فاعلية بعض الانشطة التربوية في تتمية مفهوم الاختلاف و التعددية الثقافية وقبول الاخر لدى طفل الروضة

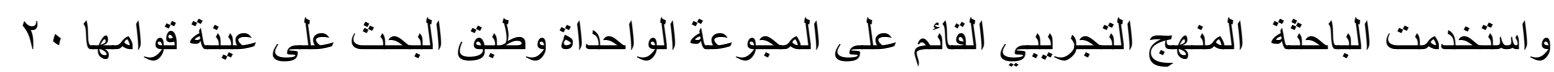
طفل وتم تطبيق اختبار قياس مفهوم مفهوم الاختلاف و التعددية الثقافية وقبول الاخر تطبيقا قبليا وتطبيقا بعديا بعد تطبيق التجربة الرئيسية وهي الانشطة التربوية المقترحة لتنمية مفهوم الاختلاف والتعددية التقافية وقبول الاخر ودلت النتائج على فاعليه الانشطه التربوية المقترحة في تنمية مفهوم الاختلاف والتعددية الثقافية وقبول الاخر لدى الاطفال ويوصي البحث بالوعي بأهمية مفهوم تقبل الاخر وتتميته للطفل في مرحلة الطفولة المبكرة و ضرورة تضمين برامج الطفولة المبكرة لمفاهيم احترام وتقبل التعددية الثقافية و اختلاف الاخر. 


\section{The effectiveness of some of the Educational Activities in Developing the Difference, Multicultural and Acceptance of the other Concept to children}

The research problem lies in dealing with the idea of developing the principle of accepting difference with the other and multiculturalism, especially after technological developments that contributed to changing societal values, so it was necessary to work on raising the child in early childhood on how to accept this difference and cultural diversity, and educational activities are part Important in the kindergarten, where these activities are presented to the child in the kindergarten in order to practice them and then talk about them in his language and train in the expression more than once and then review himself to amend the expression in order to be more accurate so there is a need to do this research which is to suggest some educational activities that help in developing the concept of accepting the Another variation and the multiplicity of cultures

The researcher used the experimental approach based on the one group A test was applied to measure the concept of difference and cultural pluralism and acceptance of the other before and after applying the main experience, which is the proposed educational activities to develop the concept of difference and cultural pluralism and acceptance of the other The results indicated the effectiveness of activities The proposed educational development in the concept of difference and cultural pluralism and acceptance of the other in children. The research recommends awareness of the importance of the concept of accepting the other and developing it for the child in early childhood. 
ويقابل جيع المجتمعات في الفترة الاخيرة الكثير من التحديات والتغيرات التي تتنج نتيجة

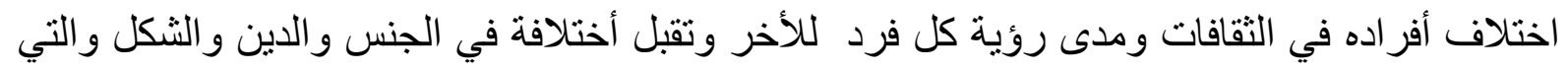
ينتج عنها حدوث المشكلات السلوكية والاجتماعية وتنتج بعض الافكار التطرفية والتنمر على التى الاخرين

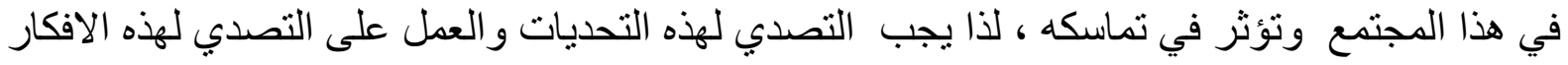
والقدرة تزيز الافكار الايجابية في قدرة الافراد على تقبل الاخر وادر اكهم لمفهوم الاختلاف ليكون

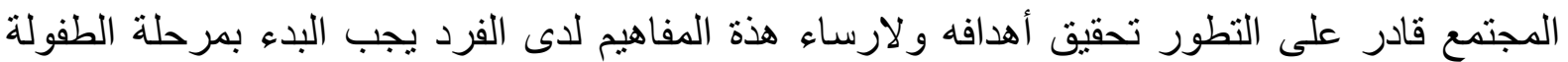
لاهميتهاو الاستثمار فيها والتي تعد أساس التنشئة وترسيخ المفاهيم و السلوكيات السوة السية

وتعد الطفولة هي أساس التكوين الذي من الضروري الاهتمام بتنشئتها لتكوين شخصية الفرد في

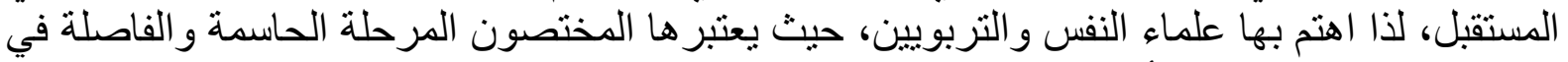
تشكيل الصفات و المبادئ الأساسية للشخصية التي توضح المؤهين هلات الخاصة للفرد في مجتمعه.

حيث تعد مر احل النمو التي يمر بها الطفل هي امتداد لبعضها البعض، حيث تعد بأنها الأساس والتي

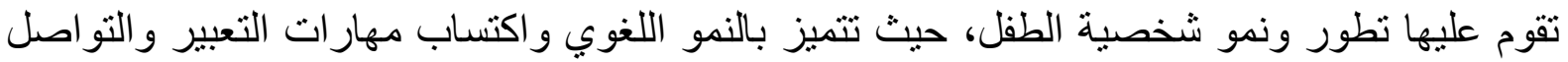

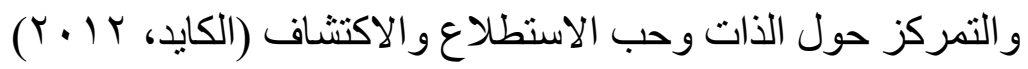

تختلف الثقافات وتتعدد داخل المجتمع الواحد، لذا من المهم على الفرد عند التفاعل مع اقرانه في

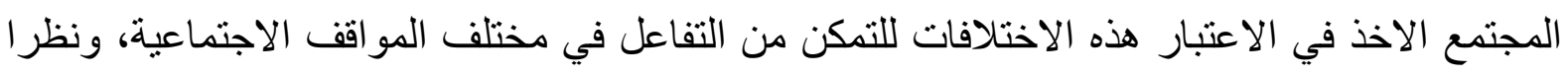
للأهمية العظيمة لقدرة الفرد على قبول الاخر في الحياة، اكدت كل الديانات السماوية على الالتزام به لما

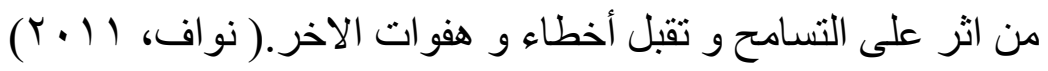
ويعد تقبل الآخر هو تقبل و احترام الآخر و قبول الاختلاف وتقدير وتفهم ما لدية من افكار وتقاليد

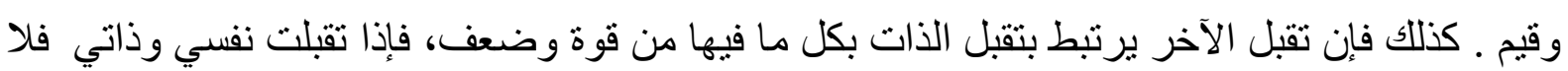

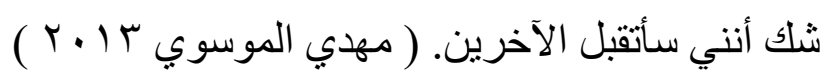

لذا يتضح لنا أهمية مفهوم تقبل الاخروتقبل الاختلاف والتعددية الثقافية في العصر الحديث حيث انها تعد جزء من تقبل الفرد لذاته وقدرتة على العيش في مجتمعه طريق سوية وايجابية

ان القبول هو الاحتفاء بالآخرين كما هم بلا شروط وتقبلهم على علاتهم وحقيقتهم ومقاومة رغباتتا الداخلية في تغيير هم ليصبحوا كما نرغب ونريد وان نتعايش معهم بكل لطف ومحبة وبن وبدون قسر او تعنيف وان نفتح لهم نو افد الحياة ليظهروا افضل ما لديهم وفي الاحوال علينا تقبل حلالتهم و قدر اتهم.

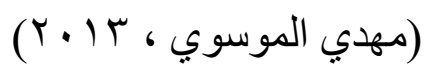


لذا وجب علي الانسان تقبل الاخر فمن باب اولي تقبله لذاته وتصالحه معها كيفية علي تقبل الاخرين و التفاعل معهم بطريقة ايجابية و عدم ثقته بنفسه تجعله يشعر بالنقص و العجز و الفشل مما يدفعه الي والي

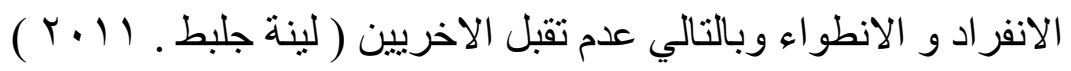

ويأتي اهمية مرحلة الطفولة حيت يتم فيها تطوير في الصورة الذاتية الاجتماعية للطفل لاحد اساسيات تقبل الاطفال الاختلاف وتفهمه للتعددية الثقافية ويجب اتاحة الفرصة للاطفال لتنمية مهار ات الاطفال الجسمية و الحركية ومهارة التعبير عن الانفعال و التحكم فيه و المهارات الاجتماعية مثل التكيف الاجتماعي وصورة الذات وتعزيز احترام الذات الايجابي و التنوع و المساواة ( ححيت جوزيف . $(Y \cdot 10$

وبما ان مرحلة الطفولة هي من أهم المراحل التي يمر بها الفرد في حياته حيث تتاسس بها اتجاهاتة وتتكون قدر اته ومهار اته لذا يجب الاهتمام بترسيخ هذه المفاهيم الهامه لدى الطفل و العمل على تنميتها لخلق جيل واعي ونتجنب المشكلات السلوكية والاجتماعية الناجمة عن عدم الوعي بهذه المفاهيم

\section{مشكلة البحث:}

تكمن مشكلة البحث في تناول فكرة تنمية مبدأ تقبل الاختلاف مع الاخر و تعدد التقافات خصوصا بعد

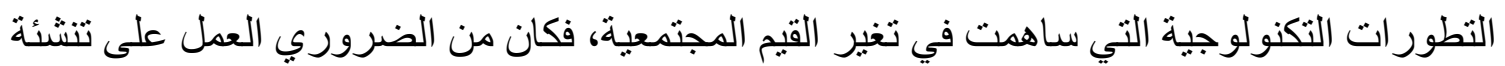
الطفل في مرحلة الطفولة المبكرة على كيفية تقبل هذه الاختلاف و التعدد الثقافي، وقامت الباحثة بدر استة استطلاعية عن مفهوم الاختلاف في روضة سمير التجريبية على عينة من الاطفال عددهم ( • ( ) أطفال

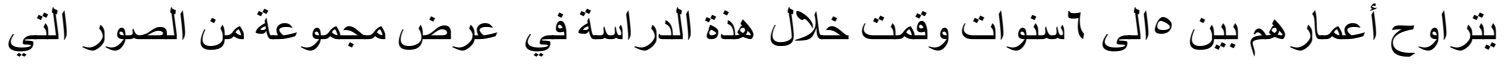

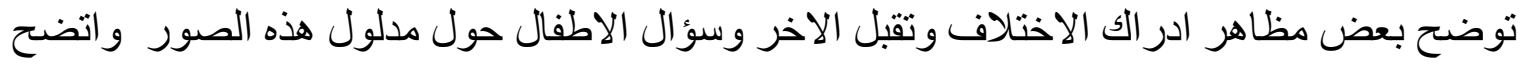

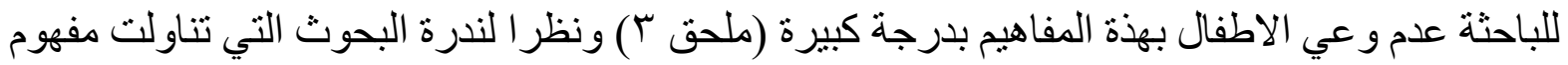

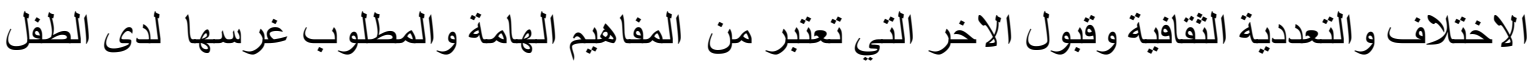

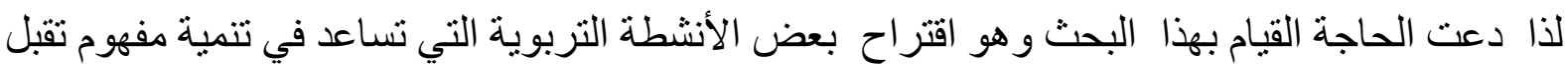
الاخر والاختلاف و تعدد الثقافات.

تساؤلات البحث:

ما فاعلية بعض الانشطة التربوية في تنمية مفهوم الاختلاف و التعددية الثقافية وقبول الاخر لدى طفل الروضة وينبثق منه تساؤ لات فر عية ا ـ ماهي الانثطة الانشطة التربوية المقترحة لتنمية مفهوم الاختلاف و التعددية الثقافية وقبول الاخر

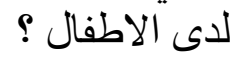
r- ماهية مفهوم الاختلاف و التعددية التقافية وقبول الاخر لدي الاطفال؟

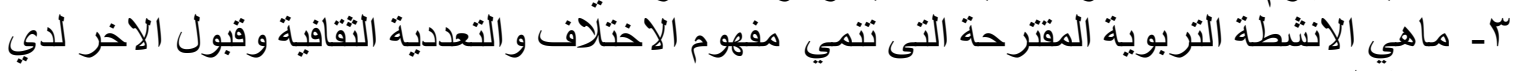

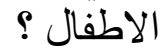




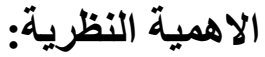

1 ـ ندرة البحوث التي تتاولت موضو ع مفهوم الاختلاف و التعددية الثقافية وتقبل الاخر

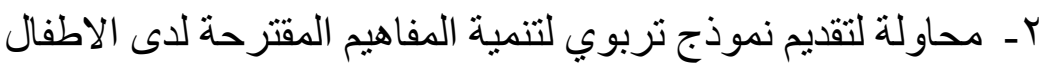

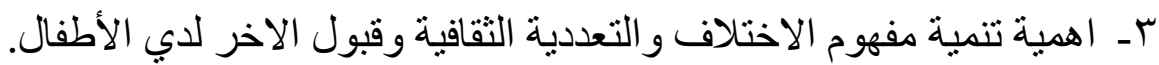

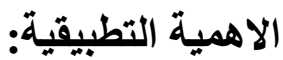

1- تقديم أنشطة تربوية مقترحة في تتمية مفهوم الاختلاف و التعددية الثقافية وقبول الاخر r ـ تقديم بعض الاقتر احات لتصميم انشطة تربوية لتتمية مفهوم الاختلاف و التعددية الثقافية وقبول الاخر rـ مساعدة الاطفال لتنمية مفاهيم الاختلاف و التعددية الثقافية وقبول الاخر من خلال انثطة تساعد في

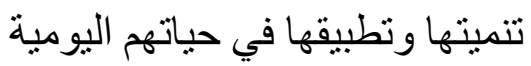

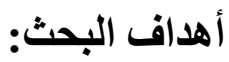

يسعى هذا البحث لتحقيق الأهداف التالية:

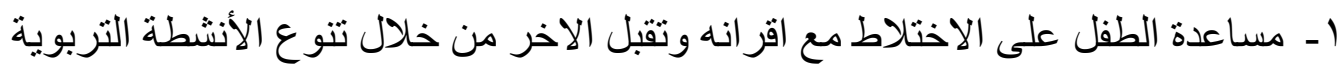

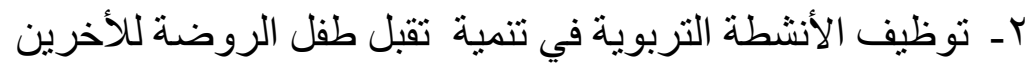

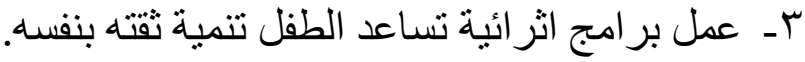

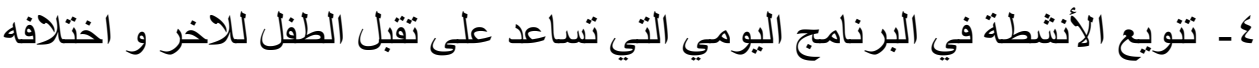

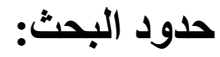

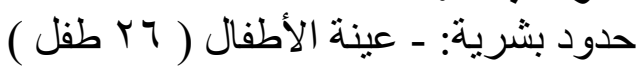

$$
\begin{aligned}
& \text { حدود مكانية: - روضة - رونة ابن انس التجريبية }
\end{aligned}
$$

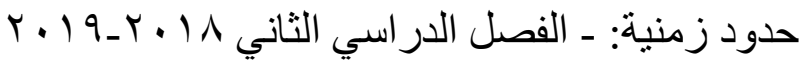

$$
\begin{aligned}
& \text { حدود اكاديمية: - - الإنية }
\end{aligned}
$$

1 - الانشطة التربوية لتنمية دفهوم الاختلاف و التعددية التقافية وقبول الاخر لدي الاطفال r- مقياس مفهوم الاختلاف و التعددية الثقافية وقبول الاخر لانية لإي الاطفال

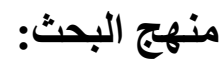

$$
\text { المنهج التجريبي القائم على المجو عة الواحداة }
$$

ا - توجد فروق داله احصائيا عند مستوي 0.01 بين منوسطي درجات المجمو عـه التجريييه في

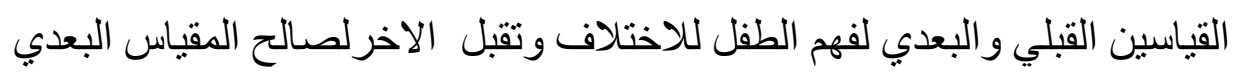

r-للانشطة التربوية المقترحة أثر تربوي على الاطفال عينة البحث لتنمية مفهوم الاختلاف والتعددية

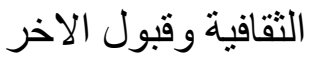
أدوات البحث (اعداد الباحثة ):

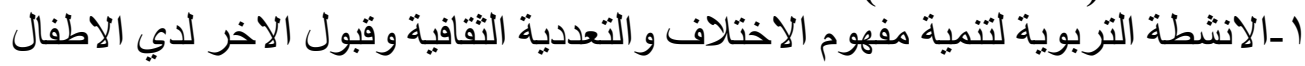

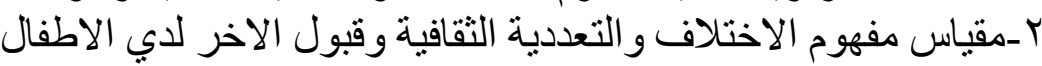




\section{- الانشطة التربوية Educational activities (يوسف قطاني. ^... ) )}

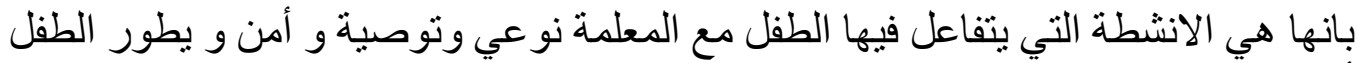

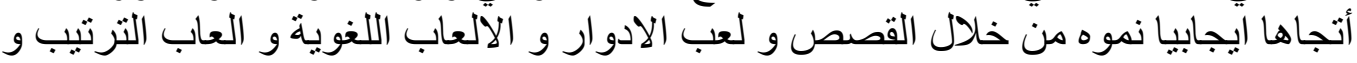
التصنيف و الرسم و الالوان الحركة.

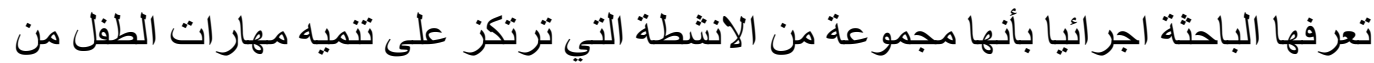

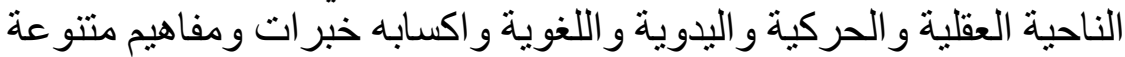

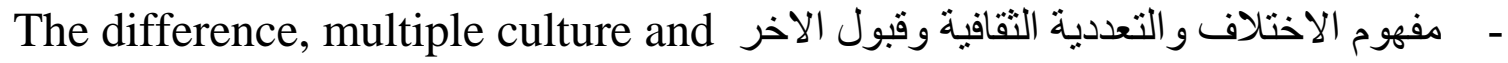
(حسن. ع ( $)$ acceptance of the other concept

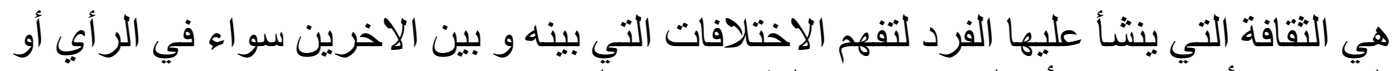

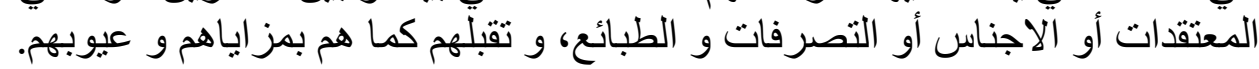

تعرفها الباحثة اجر ائيا بأنها مسألة تربوية تدرييية لابد ان يتربى عليها الصغير منذ سنو اته الاولي و لا

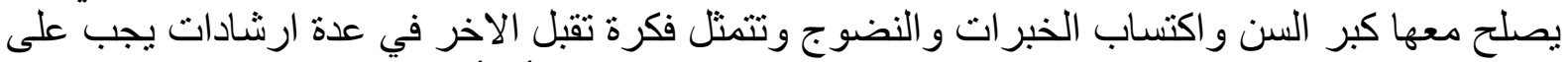

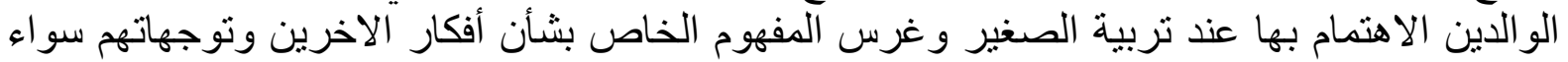

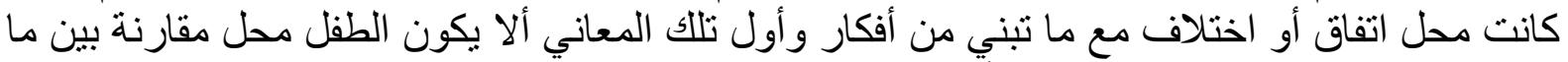

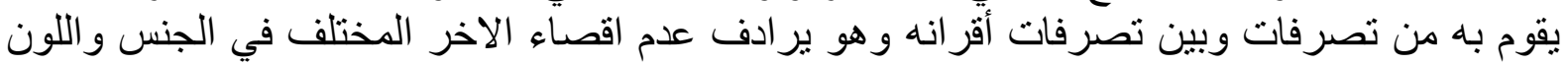
و الثقافة ويقصد به التعايش مع الاخر

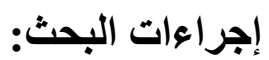
اتبعت الباحثة الإجر اءات و الخطو ات التالية:

الاطلاع على بعض الدر اسـات السـابقة في مجال تتميـة مفهوم الاختلاف و التعدديـة الثقافية وقبول

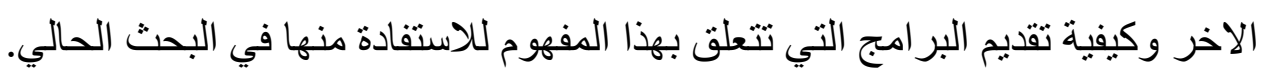
تصميم اختبار مفهوم الاختلاف والتعددية الثقافية وقبول الاخر وتقنينه. إعداد أنشطة تربوية تسهم في إكساب الاطفال مفهوم الاختلاف و التعددية الثقافية وقبول الاخر إعداد وتصميم اختبار مفهوم تقبل الاخر وضبطه وتقنينه. تطبيق اختبار مفهوم تقبل الاخر قبلي على المجموعة التجرييية.

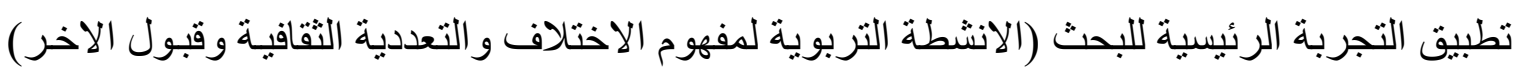
على المجمو عة التجريبية تطبيق اختبار مفهوم تقبل الاخر تطبيقاً بعدياً على أطفال العينة "المجموعة التجريبية". تحليل النتائج إحصائياً وتفسير ها. التوصيات و المقترحات الخاصة بالبحث. 


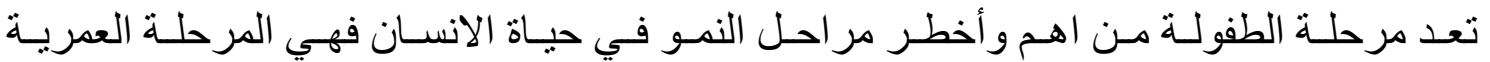

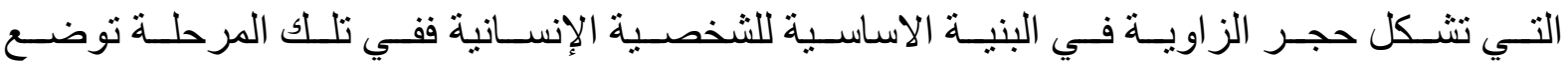

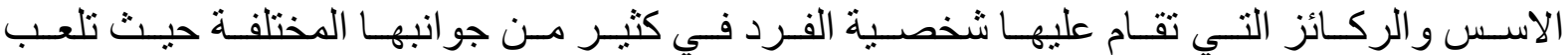
التربية دور ا هاما و أساسيا في هذا الثأن.

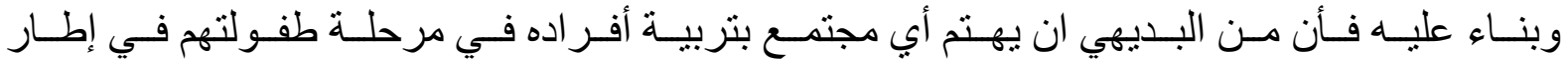

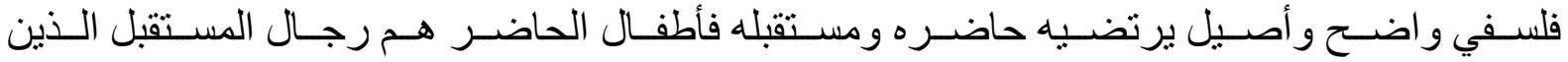
سوف يعملون ويفكرون ويقررون بصفتهم قادة المجتمع وسادته فيما بعد.

ولـذلك فـالأمر يحتــاج الـي الـوعي و الادر الك الكامـل للخطـورة و اهميـة تربيـة الاطفــال و العنايـة بهـم حتى يمكن للمجتمع ان ينظر الي مستقبله القريب و البعيد نظرة كلها اطمئنان و أمان و ثقة.

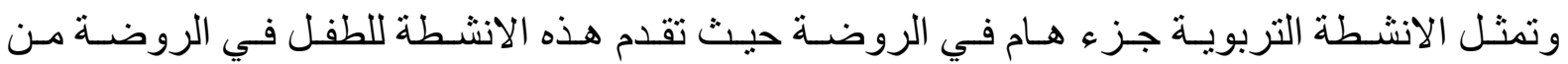

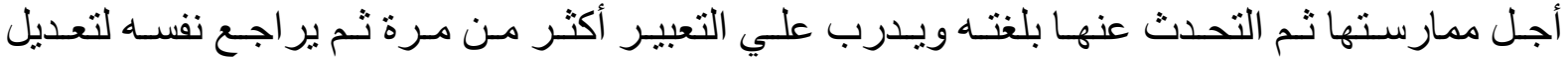
التعبير لكي يكون أكثر دقة.

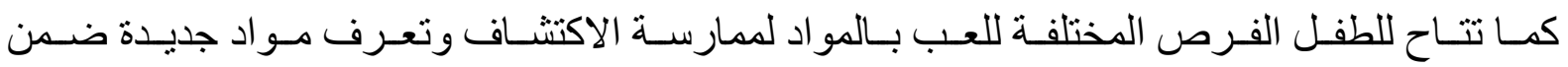

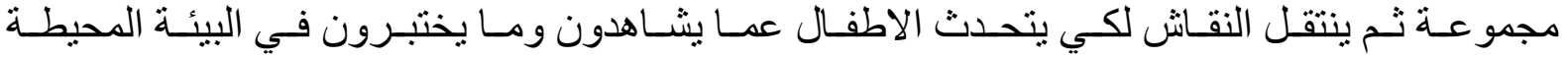

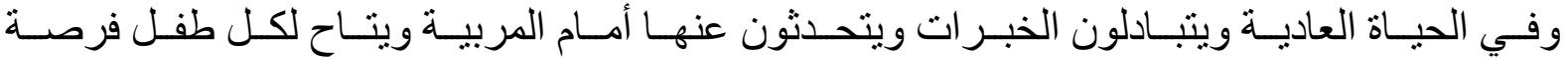

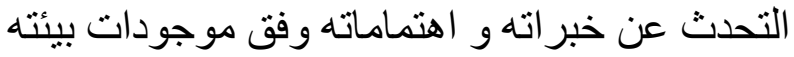

مفهوم الاختلاف والتعددية الثقافية وقبول الاخر

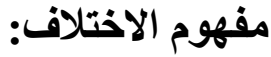

يعرف الاختلاف في اللغة بأن يأخذ كل فرد طريقا غير الاخر في حاله أو موقف أو قول، والاختلاف أكثر عمومية من التضاد، فكل متضادين مختلفين وليس العكس. (إبر اهيم، ع . . ب) عند الحديث عن تقبل الآخر لا بد من تناول العديد من المعطيات، من هو الآخر، ماذا نعني بتقبل الآخر. من هو الآخر المختلف؟ هل الآخر هو كل ما يختلف عنا، أو نختلف عنه أو لا يشبهنا سواء من حيث اللون، الجنس، العادات،

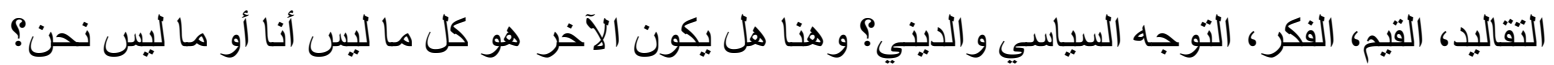

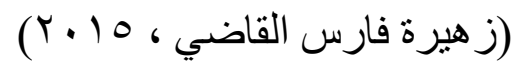
ان التعددية الثقافية والاختلاف في الثقافات كما يثير (Bennett,1999 ) فهي المصطلح البديل و الذي يعتبر مقبو لا أكثر من الاستيعاب لما يتسم به من التقدير المتبادل و الاحتر ام بين المجموعات الثقافية 
، و المجتمع المتعدد الثقافات يسمح للأفراد من الجماعات الاثنية المختلفة بالاحتفاظ بتقاليدهم و هويتهم

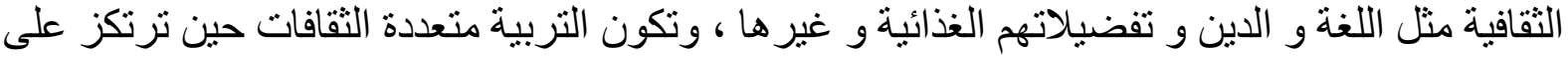
القيم والمعتقدات الديموقراطية ، و على الافتراض بأن الهدف الأول للتربية هو تشجيع النمو العقلي و ولئه الاجتماعي و الثخصي لكل الطلاب و لأقصى إمكانياتهم .

وتركز الانشطة على الحد من الصور النمطية السلبية التي ير اها الأطفال في ما حولهم من شاثات التلفاز

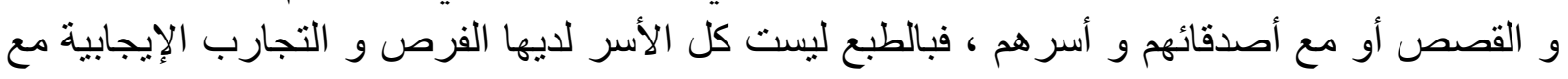

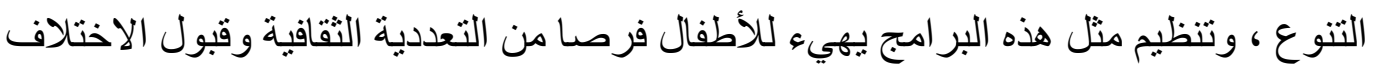

ولللك فان البرنامج الموجة للاطفال في سن الطفولة المبكرة ينبغي أن يتضمن العمل علي تنمية وعي الاطفال بأوجه التماتل و الاختلاف و مساعدتهم علي اعتبار ذلك ( امر ا طبيعيا ) وتؤكد الادلة البحثية التي توصل اليها ديفيد مبلز ان الاطفال يكتسبون مشاعر ايجابية و سلبية حيال الجماعات العنصرية منذ سن مبكر وقد لاحظ ميلز ان الاطفال حتي سن الثالثة يظهرون و عيا بعنصرية هرمية تتو افق وتتسق مع تيار صور التعصب لدي الكبار وقد يكون بعض الاطفال محدودين في نمو هم بسبب اعتقادهم بأن هنالك

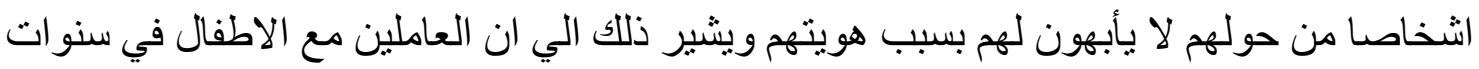
حياتهم المبكرة يجب ان يقدمو الجميع الاطفال التوجيه و الارشاد و المستندة لكي يكتسبو اتجاهات

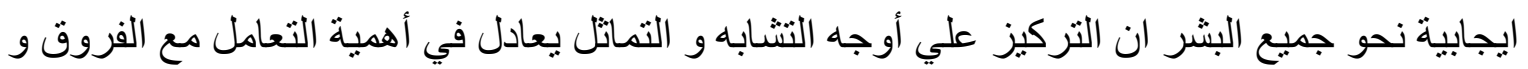
الاختلافات الانسانية ( نظر اسر اج بلا تشفورد و ماكليودبر ودينيل ) وتعد سنوات الطفولة الاولي الوقت

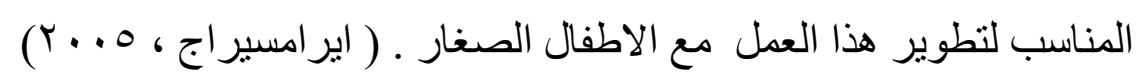

تعريف تقبل الآخر:

تقبل الآخر يعني احتر ام الآخر وتقدير وتفهم ما لاية من مجموع المفاهيم التي ذكرت سابقا من أفكار وتقاليد وقيم الخ.....، كذلك فإن تقبل الآخر يرتبط بتقبل الذات بكل ما فيها من قوة وضعف، فإذإن تقبلت نفسي وذاتي فلا شك أنني سأتقبل الآخرين. هناك فهم خاطئ لاى الكثيرين من تقبل الآخر لاعتقادهم أن تقبل الآخر يعني الذوبان فيه وأن الفرد يمكن أن يخسر ما لايه وبالتالي يفقد انتمائه لذاته، و أنه سيعطي للآخر قيمة على حساب نفسه، و هذا بتقديري مفهوم ضيق ومحدود، أو أن الأخر يرتبط بالمجهول و هنالك في معظم الأحيان تخوف من المجهول، وهو تخوف مشروع ولكن علينا أن ندخل عالم المجهول لكي يصبح معلوماً. ففي مرحلة المراهقة والثباب، يبدأ الفرد بالاستقلالية وتحقيق الذات، يبحث عن هويته الدينية، السياسية، الوطنية، الفكرية و الجنسية، ويكون في الغالب متحيز المنظومة الانتماءات التي يبدأ في

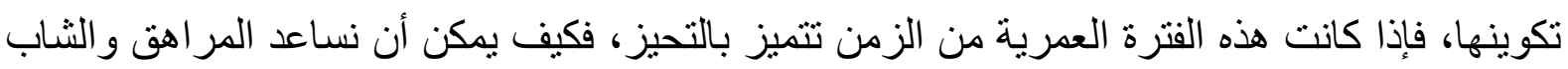
في أن يكون قادرا على أن يرى الآخر ويتعرف علية، بل ويمكن أن يوجه تحيزه لمنظومة الانتماءات، باته

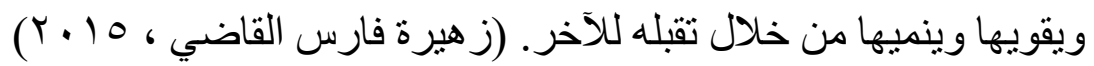
ترتبط معرفة الذات وتقبلها بمعرفة الآخر وتقبله، فالطفل الذي لايه التقة بنفسه يثق بالآخرين، وير غب في

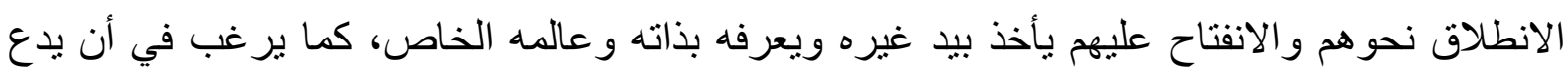


الآخرين يدخلونه إلى عو المهم، ويعرضون عليه مشاكلهم الخاصة، وبهذه الطريقة تكمل الدورة نفسها

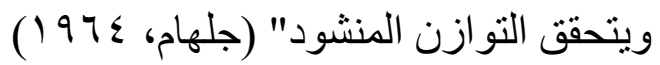

إن الطفل حديث الو لادة لا توجد لدية فكرة عن نفسة ككائن منميز عن عالمه الخارجي ، وعن الأشياء المحيطة به ويرى بياجية 'إن المواليد في الأشهر القليلة الأولى غير قادرين على التمبيز بين أنفسهم أو لونئ ذو اتهم ،و افعالهم و الاثياء المحيطة بهم والتي يمكن ان يستخدموها في افعالهم لكنه يرى أيضا أن مفاهيم الذات تسبق في الهور و التكون مفهوم الاخر او الاخرين (بهادر ، 9191 )

وقد تتاولت بعض الدراسات اهمية ثقافة الحوار وتقبل الاخر منت در اسة caliskan2012 الى تطوير الميل الى تقبل الاخر وتحليل اتجاهات طلاب المدارس الابتدائية وهدفت در اسة قاسم خزعلي واخرون الى الكثف عن اثر استر اتيجية (jigsaw II) في التعلم التعاوني في تتمية التسامح الاجتماعي

\section{أهداف قبول الاخر عند الاطقال :}

من الضروري السعي الى تعليم الأطفال في سنواتهم المبكرة و تنميتهم على قيم و ثقافة قبول الاخر، و ذللك لتحقيق العديد من الأهداف الاجتماعية و التربوية التي يمكن ذكر بعضها فيما يلي:

- ـ الدراية الكاملة و الوعي بأصول تقبل الاخر، لما له من اثر في استثارة المشاعر التي تتعلق بالاتفاق حول القضايا الخلافية الداخلية و الحد من مشاعر البغض ول ولاهر التعصب. - التأكيد على رفض الاقصاء والتهميش و العنف ضد الاخرين، و التوجه الى الحوار العقلي الحر و المقبول في سياق الموضوع أو القضايا. - الاتجاه الى تفعيل دور الحوار مع الاخر و تقبله باستخدام وسائل الاعلام المختلفة، و التشجيع

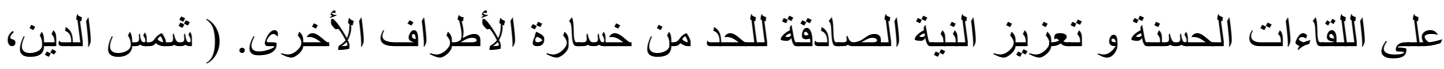

استقر في أذهان الكثيرين حتى وقت قريب أولوية الجانب المعرفي العقلي في تحديد نجاح الطفل في

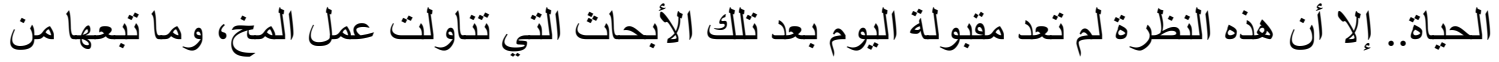

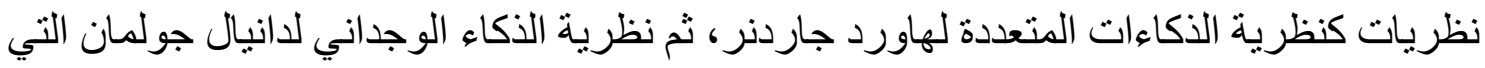

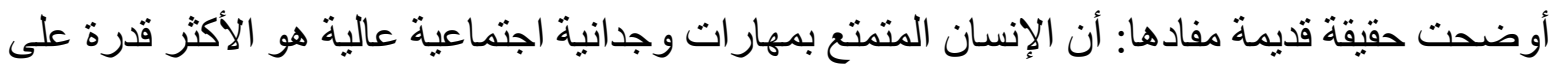

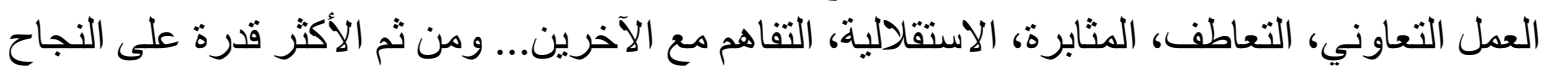

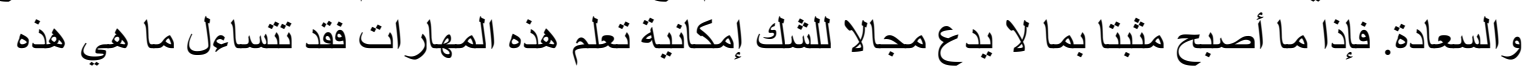
المهار ات الت 
ويمكن تنمية فهم الطقل للآخرين من خلال:

ا-تقدير الأخرين :

-تمبيز وقبول الاختلافات في الأخرين

ـتمييز القدرات ، المواهب الخاصة الأداء المتميز للأخرين

بـ فهم مشاعر الأخرين :

ـتمبيز و احتر ام مشاعر واحتياجات الأخرين

ـفهم تأثير سلوكه الثخصي على مشاعر وسلوك الأخرين .

ب-مهارات العيش في جماعة :

ـالقرة على التفاهم مع الأخرين و التعاون داخل مجموعة ـالقدرة على الدخول في صداقات

ـالقدرة على النتارك (الأخذ و العطاء ) مع الأخرين .

ـتمبيز مز ايا العمل مع الأخرين.

-فهم وتلمس الاحتياج للقو انين والاتفاقات

ـالقدرة على وضع قو انين واتفاقات و العيش في ظلاها.

ع ـتعلم فض التزاعات:

ـتنمية الحلول الملائمة لحل الاختلافات

ـأن ير اء دورة أو دور غيرة في تصاعد أو تهدئة الخلافات

ـتعلم التعامل مع ضغط الرفاق. ( نيفين عبد الله ، . . . F )

ولتنمية هذه المهار ات يمكن الاستفادة من المواقف اليومية التلقائية التي يمر بها الطفل من من القواعد

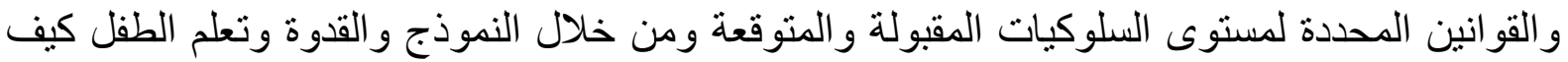


يتشارك ويمارس أنشطة للعمل التعاوني وتنمية القدرة على المثابرة و التحكم في الاندفاع وفهم مشاعره و التفكير في بدائل للعب بطرق مقبولة مع الرفاق هناك عدة موضو عات مرتبطة بتنمية مفهوم الاختلاف و التعددية التقافية وقبول الاخرمنل

الطقل و التكيف الاجتماعي

ويعتبر تكيف الطفل اجتماعيا : القدرة علي مواجهة الصر اعات الداخلية بين الدو افع الداخلية و الخارجية

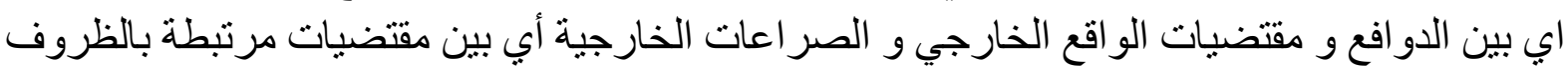

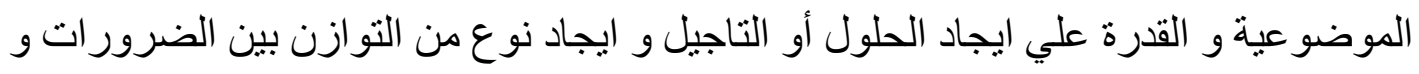

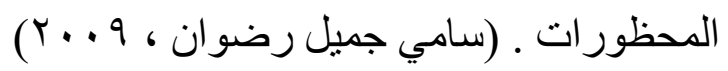

ان من المسلم به علي نطاق واسع ان هنالك حاجة الي تبني مدخل متكامل وشامل وتتموي فيما يتصل

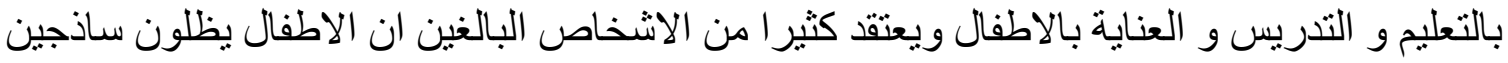

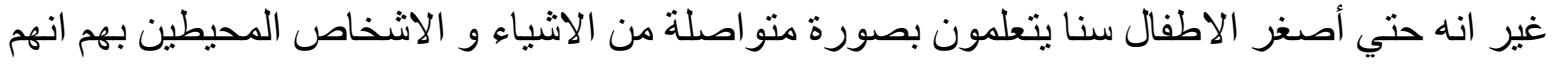

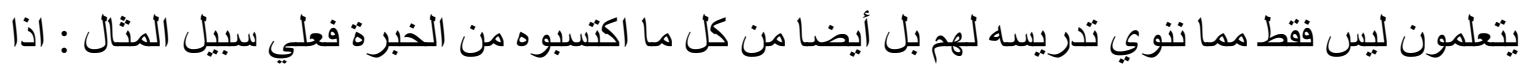

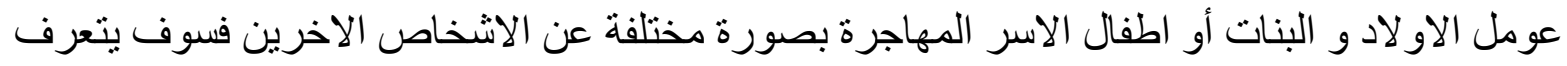

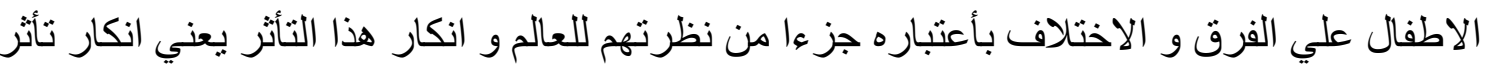

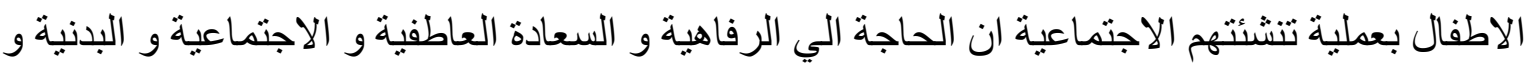

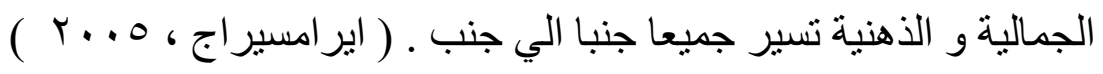

\section{تعزيز احترام الذات الايجابي}

ويمثل تعزيز احتر ام الذات الايجابي يلعب التربويون المتعاملون مع الاطفال في مرحلة الطفولة المبكرة دور جو هريا في هذه الناحية من نواحي نمو شخصية الطفل حيث يجب ان يساعدوا الاطفال علي تعلم كيفية توجيه سلوكهم علي نحو يظهر الاحتر ام و المر اعاة تجاه انفسهم و الاطفال الاخرين و الكبار و • بيئتهم المباشرة و الخارجية

ومعرفة الاخر وتقبله هي الوجه المكمل لمعرفة الذات وتقبلها ولذا فأن علي المعلمة ان تعمل علي ان يتعرف الطفل علي ذوات الاخرين كما ينعرف علي ذاته وان يتقبل ذوات الاخرين كما يتقبل ذاته وهنا يمكن ان تتبع المعلمة في وحدة تقبلا لاخر لنفسه ما اتبع من الانشطة وطريقة تتفيذها في الوحدة اعرف نفسك مع الفرق ان المناقثات و الحوارات تدور حول ذات الاخر الجسميةو الاجتماعية و الانفعاليةو توجه المعلمة الانتباه اثناء الانشطة و الحوارات المرتبطة بها علي تقبل الاخرين كما هم و التأكيد علي مبدأ المساو اة بين الجميع وفي نفس الوقت علي المعلمة ان تلفت نظر الطفل الي ان هنالك فروق فردية بينهما ينبخي مر اعتها واحتر امها بالاضافة الي التعرف علي ادوار الاخرين الاجتماعية و مو اقفهم من السلطة (علاء الدين كفافي ـ و اخرون . 1 . . ب ) 
ويعكس أدب الاطفال من خلال الرسومات فيها صورة العالم يوجدفيه تقريبا أطفال بشترتهم غامقة أو أو أونات ذوي أعاقة معظم أبطال القصص هم أو لاد وليسو ا بنات هنالك عدد قليل من الكتب يحاول أن يعرض التها

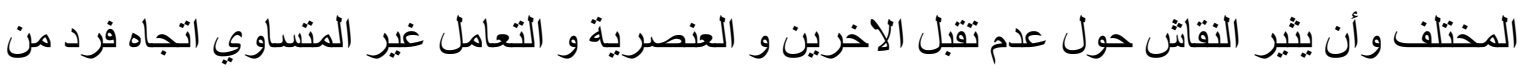
المجموعة لذا يوصى باقتناءمثل هذة الكتب لمكتبة الروضة وتثجيع الحديث و النقاش بعد قر ائتها من

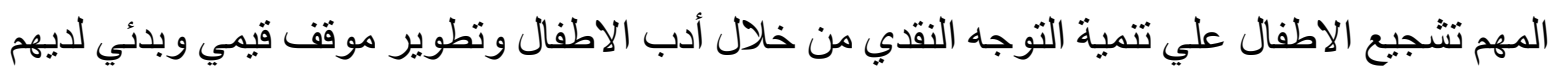

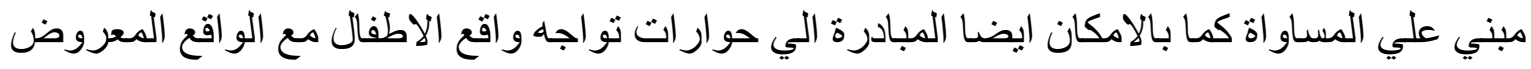

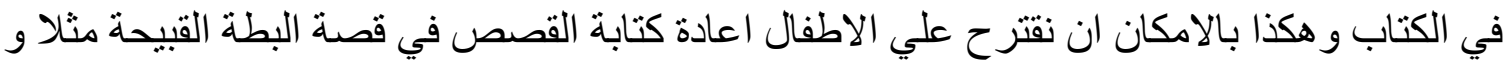

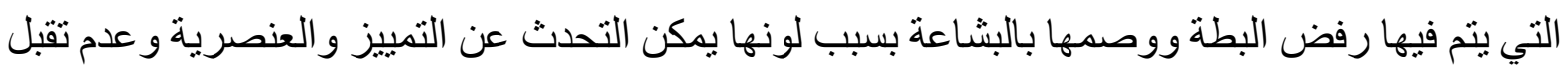

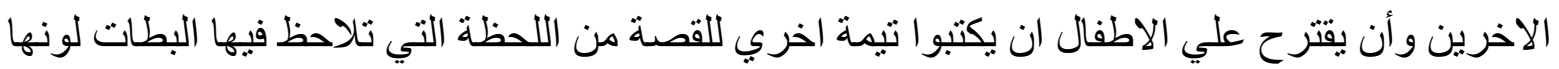

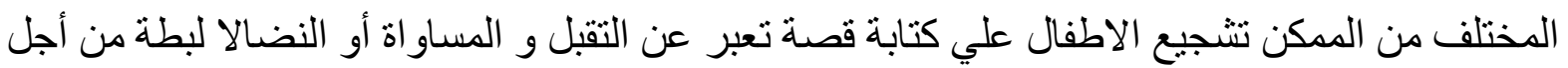

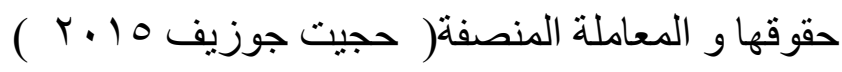

تمحورت مجموعة من الابحاث في الو لايات المتحدة حول تأثثر العنصرية علي التصور الذاتي عند

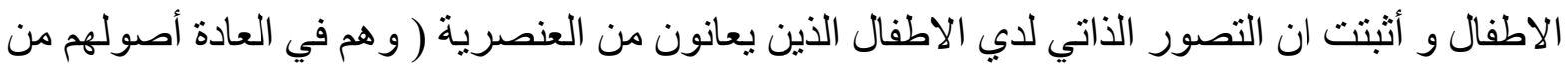

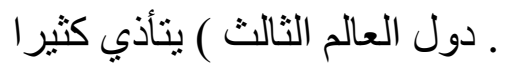

ان القبول هو الاحتفاء بالاخرين كما هم بلا شروطو تقبلهم علي علاتهم وحقيقته ومقاومة رغباتنا

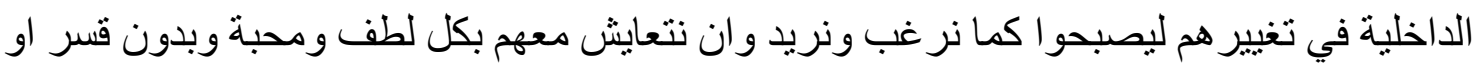

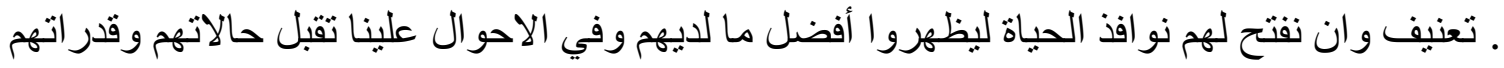

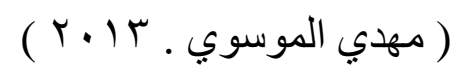

\section{أهمية تنمية مفهوم التعددية وقبول الاختلاف وتقبل الاخر:}

ان تربية الطفل وتنتئتهم هي عملية مستمرة وديناميكية تنطلق من الاسرة او لا بوصفها حجر الاساس في الاسي

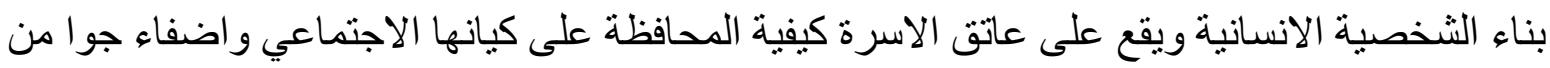

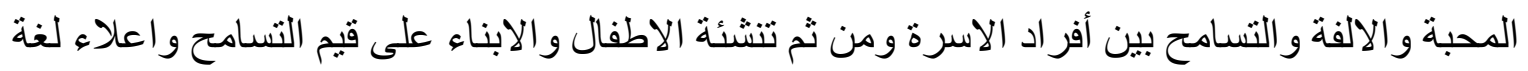

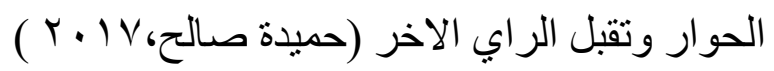

كما تكمن أهمية مفهوم الأنا والآخر للى طفل الروضة من خلال

1 - الكثف عن الأنا (الذات) وتحديد مكانتها بالنسبة للإنسان عموماً وللطفل على وجه الخصوص.

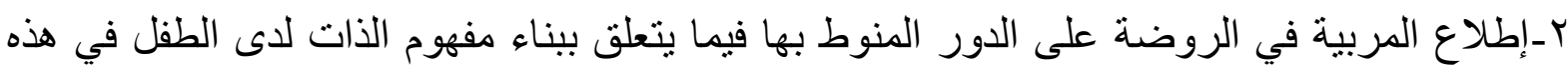

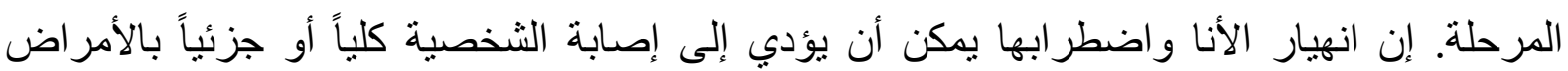


و الاضطر ابات النفسية، ومن هنا كان لابد من التأسيس الجيد لهذا المفهوم، و العمل على اكتشافه وفهمه من قبل الطفل بشكل مبكر . من مبن

r-إضافة إلى نقص الاهتمام بمفهوم الأنا أو الذات، وكيفية بنائه وتحصينه في المؤسسات التربوية المعنية

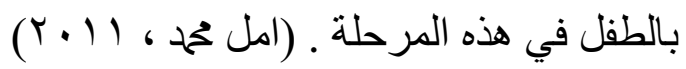

\section{العوامل التي تشاعد على تقبل الاختلاف و تقبل الاخر:}

تسهم العديد من العو امل في مساعدة الطفل على تقبل الاختلاف بينه وبين الاخر سواء من حيث الثكل -

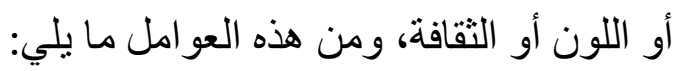

- العامل الديني: يعد هذا العامل من اهم العوامل الذي له دور أساسي في مساعدة الطفل على تقبله

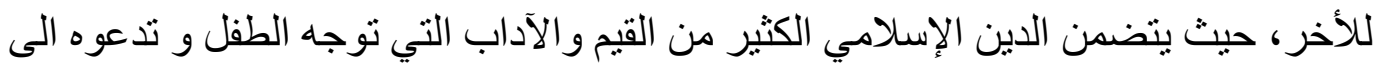

الاخر بصرف النظر عن دينهم أو جسهم أو لغتهم، حيث يحث الدين الإسلامي و الأديان

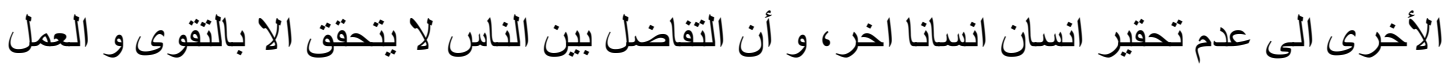

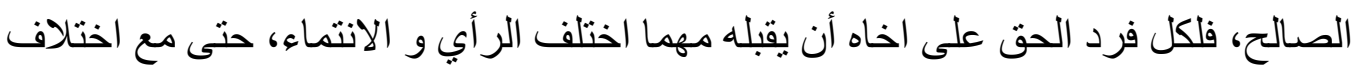
الأديان، فديننا الإسلامي يمنع التعصب للأديان و الحقد المكبوت ضد اهل الديانات السماوية، و وله

$$
\text { يؤكد على ضرورة التعامل الحسن معهم. (النصر ، } 1 \text {. . ب ) }
$$

- الر ابط الاسري: من الضروري أن يشعر الفرد منذ مرحلة الطفولة بالميل و الحب و تقبل من تربطه بهم رابط اجتماعي أو اسري أو روابط قر ابة، فالفرد يميل بطبعه الى من يلتقي معهم بالدم

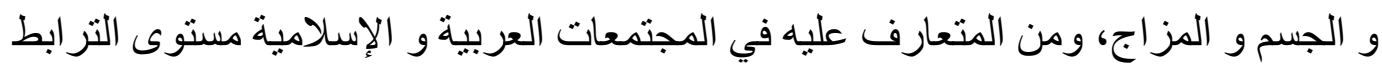
الاسري القوي و مدى انتشار الروح التعاونية بين افر ادها. - العامل النفسي: يعد العامل النفسي من أكثر العو امل التي لها دور في القدرة على تقبل الفرد للآخر ، فمع تناول العديد من الباحثين هذا الموضوع اكدت الدر اسات العلمية التي تم اجر اءها أن الفرد ذو الصحة النفسية الجيدة أكثر قدرة على تقبل الاخرين ومحبتهم والثقة بهر.

يسهم هذا العامل في تمكن الفرد من العيش بسلام وصداقة مع الاخر ورغبته في العامل مع الاخر و تكوين العديد من العلاقات الاجتماعية مهما اختلف هذا الفرد معه في العقيدة أو الثقافة و

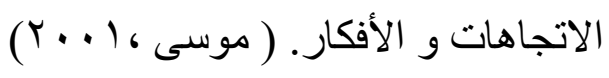

- العامل الأخلاقي: يسهم العامل الأخلاقي بنسبة ليست بقليلة في مستوى قدرة الفرد على تقبل الاخر، فالأخلاق هي الأساس الذي يحدد شكل سلوك و تصرفات الفرد مع الاخرين في المجنمع، فإذا اتسمت هذه الاخلاق بالحسنة ينتج عنها السلوكيات الحسنة مما ينم عن وجود معاملات تقوم

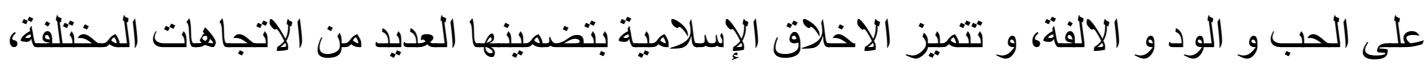

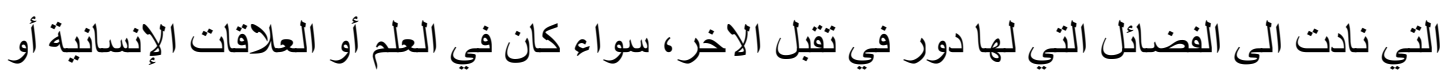


الميدان السياسي، فكان التعامل بينهم على أساس المحبة و المودة و الاخاء و التعاون و الرحمة و

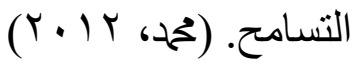

- العامل الاقتصادي: للعامل الاقتصادي دور في مستوى تقبل الفرد للاخر، فالفرد الذي يقدم

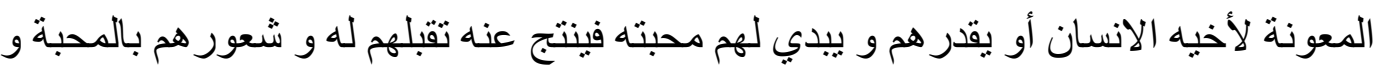
التعاطف، الى جانب الثعور بالمسئولية الاجتماعية نحو أبناء وطنه.

- العامل الاجتماعي: إن الانسان بطبعه هو كائن محب للمجتمعات، لا يستطيع أن يعيش بمعزل عن الاخرين، فهو يميل الى العيش ضمن روابطو جماعات اجتماعية و يرفض و يكره الانعز ال و الانقطاع عن الاخرين، لذا يسير الانسان طبقا لحاجاته الى المدنية و تكوين علاقات شخصية

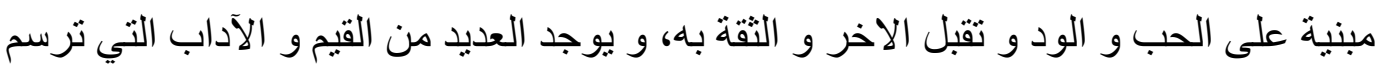

العلاقة بين الفرد و أخيه لتساعده على قبوله ومنها القاء السلام و رده و المصافحة و زيارة المريض و الإجابة الى الطعام و الدعوة اليه، الى جانب تكريم الزائر و توديعه الى الباب و عدم مقاطعة الحديث. (حسن ، 9 . . ( م)

\section{العوامل التي تمنع الطقل من قبول الاخر:}

بالإضافة اللى وجود العو امل التي تساعد على تقبل الاخر، هنالك بعض العو امل التي قد تحد من قبوله، و تتصل هذه العوامل بمختلف الجو انب النفسية السلوكية أو الأخلاقيةو بعض الأمور الأخرى التي نستعرضها فيما يلي:

- المعوقات النفسية: من الطبيعي أن هنالك فرصة لأي فرد بالتعرض لبعض الازمات و العقبات التي تقف حائلا بينه و بين التصرفات الطبيعية من حوله، و التي تحول بينه و بين احتياجاته

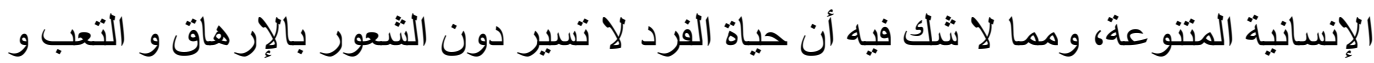
التوتر، و كنتيجة طبيعية لهذه المشاعر و الاحاسيس تؤثر هذه المعاملات و التصرفات على السلوكيات بين الافر اد اذا لم يكن هناك سبطرة عليها، مما قد ينم عن رفض للآخر و عدم الشعور

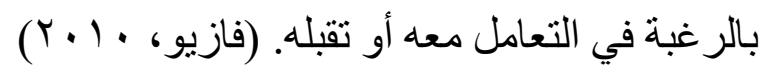

- معوقات أخلاقية وقيمية: تشير الى ما قد يوجه بعض الناس من اخلاق و سلوكيات سلبية ينتج عنها تصرفات تحول بينه و بين قبول الاخر، مثل الكبر و الغضب و الكرهو الحقد و الحسدو وهو الغيرة و الغيبة و النميمة، و مثلما تمثل القيم عو امل تساهم في تقبل الاخر، فإنها أيضا لها دور في الحد من ذلك، مثلما يحدث و ينتشر في أوقات الفوضى و التغير الاجتماعي و ما ينتج عنه من انحدار للقيم الاجتماعية. - اختلاف العقيدة: أن الحب في الله هو العامل الذي يرسم و يحدد اطار التعال مع الاخرين في تمام العبودية، لذا فالمؤمن الحق هو ما يميل الى حب من يحبهم الله و يو اليهم، فعلى المسلم أن يكون ولائه الأول الى من يكون و لائه للعقيدة الإسلامية الصحيحة. 
- اختلاف السن: تعد عملية التتشئة الاجتماعية أساسها الإباء و الأمهات الذين يميلون في العادة الى تنشئة أو لادهم على ما تربو ا عليه، لذا بحدث تضارب بين القيم و المعتقدات الحديثة و القديمة،

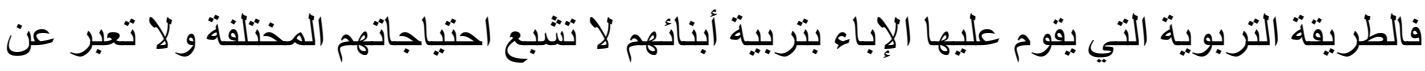

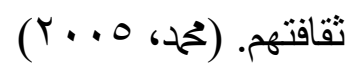
- مستوى الاقتصادي و الاجتماعي: تختلف المكانة الاقتصادية و الاجتماعية للأفر اد في المجتمع

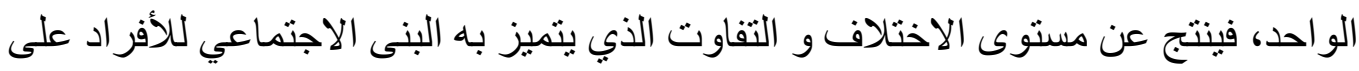

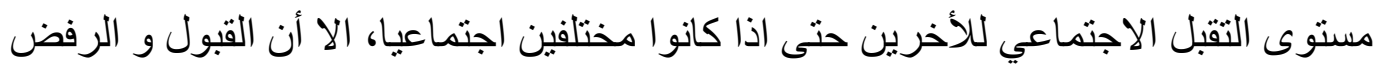

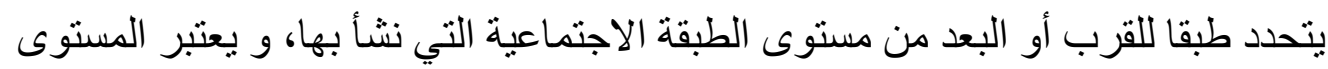
الاجتماعي و الاقتصادي من اهم العو امل التي يقوم عليها تقبل او رفض الفرد للآخر. (تحمد، $(r \cdot)$.

\section{إجراعات البحث}

تتناول السطور التالية خطوات التجريب بدءاً بالمنهج المستخدم وفروض البحث و عينة البحث و إعداد الأنشطة، ووضع والتطبيق القبلي للأدوات، وتطبيق الأنشطة على الأطفال عينة الدراسة، وأخيراً التطبيق البعدي و التتبعي لأدو ات البحث، و الأسلوب الإحصائي الذي اتبعته الباحثة في معالجة البيانات.

أولا: - منهج البحث

البحث الحالي على المنهج شبه التجريبي ذو المجموعة الواحدةالتجريبية لذا فقد قامت الباحثة بالآتي: -

1 ـ اختيار العينة وضبط درجة التجانس بين أفر اد المجمو عة.

r ـ تطبيق مقياس مفهوم الاختلاف و التعدية الثقافية وقبول الاخر قبلياً على الأطفال عينة البحث. بـ تطبيق الأنثطة على الأطفال عينة البحث ع - إجر اء قياس بعدى لقياس تأثثر الأنثطة التربوية المقترحة لتنمية مفهوم تقبل الاخر لدى الأطفال عينة البحث.

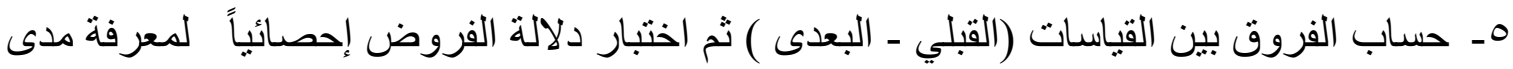
فاعلية الأنشطة التربوية المفترحة على اكتساب الاطفال (عينة البحث) لمفهوم الاختلاف و التعددية الثقافية وقبول الاخر ثانياً :- عينة البحث:-

لما كان البحث الحالي يهدف الى "تتميه الاختلاف و التعددية التقافية وقبول الاخر لدى الاطفال" تكونت العينة الأسساسية وتضمنت (·) طفل وقد روعي في اختيار العينة ضبط متغير السن ، و الذكاء و مستو اهم الاجتماعي و الاقتصادي أيضاً متقارب حيث إنهم في " روضة حكومية " و احدة ويعيشون بمنطقة 
وتشمل : البعد المكاني ، حجم العينة ، تجانس مجموعة البحث .

( ) البعد المكاني للعينة : تم اختيار العينـة من روضـة سمير التجريبيـة بإدار اة وسط التعليميـة بمحافظة الاسكندرية

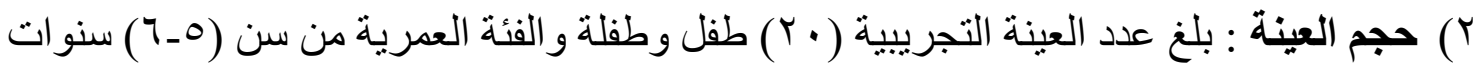
منهج البحث: المنهج التجريبي القائم على المجمو عة التجريبية الواحدة

$$
\text { فروض البحث }
$$

ـ توجد فروق داله احصائيا عند مستوي 0.01 بين متوسطي درجات المجمو عـه التجريبيه في القياسين القبلي و البعدي لفهم الطفل للاختلاف وتقبل الاخرلصالح المقياس البعدي ץ-للانشطة التربوية المقترحة أثر تربوي على الاطفال عينة البحث لتتمية مفهوم الاختلاف والتعددية الثقافية وقبول الاخر

$$
\text { متغيرات البحث : }
$$

• المتغير التابع : مفهوم الاختلاف والتعددية التقافية وقبول الاخر. (إعداد الباحثة ) • المتفير المستقل : الانشطة التربوية المقدة لأطفال المجموعة التجريبية ـ (إعداد الباحثة)

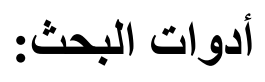$$
\text { و تشمل : }
$$

( ) اختبار مفهوم الاختلاف و التعددية التقافية وقبول الاخر ץ) الانشطة التربوية التي تنمي لدي الاطفال مفهوم التعددية الثقافية والاختلاف وتقبل الاخر اختبار مفهوم مفهوم التعدية الثقافية والاختلاف وتقبل الاخر:

قبل البدء في تطبيق الانشطة التربوية تم تطبيق الاختبار علي أطفال عينة البحث (المجموعة التجريبية ) تطبيقا قبليا ثم تم تطبيق الاختبار تطبيقا بعديا بعد تطبيق الانشطة التربوية علي أطفال عينة البحث (المجمو عة التجريبية )

\section{الأهدف من الاختبار :}

يهدف الاختبار إلى قياس مفهوم الاختلاف و التعددية التقافية وقبول الاخر لدى أطفال عينة البحث عدد الأنشطة (1 ( ) نشاط تتنوع بين الأنشطة (معرفية وحركية وفنية ودر اما ) 


\section{التجربة الرئيسية للبحث :}

قامت الباحثة بتقديم بعض الانشطة التربوية ( معرفية ـ فنية ـ در اما ـ حركية ) التي تنمي لدي

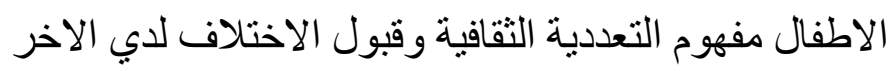

قامت الباحثة بتطبيق التجربة الرئيسية للبحث على الأطفال عينة البحث (المجموعة التجريبية)

$$
\text { تحليل مفردات المقياس: }
$$

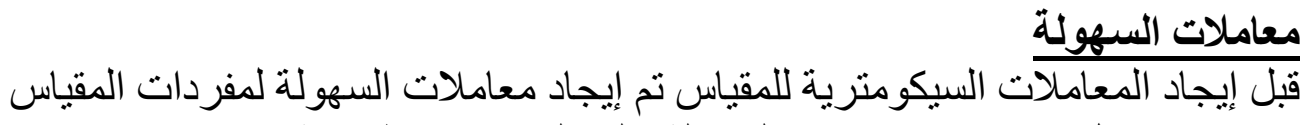
ويوضح جدول( (1) نتائج معاملات السهولة علي العينه الاستطلاعية معاملات السهولة لمفردات المقاييس التلاته:

\begin{tabular}{|c|c|c|c|c|c|}
\hline \multicolumn{2}{|c|}{ الاختبار الثالث } & \multicolumn{2}{|c|}{ الاختبار الثاني } & \multicolumn{2}{|c|}{ الاختبار الاول } \\
\hline معامل السهولة & رقم المفردة & السهولة & رقم المفردة & السهولة & رقم المفردة \\
\hline.,$\varepsilon$ & 1 &.,$\wedge$ & 1 &., $1 Y$ & 1 \\
\hline . & r &., $1 Y$ & r &.,\{ & r \\
\hline$\cdot$ & r & . & 3 &.,$\wedge$ & $r$ \\
\hline . & $\varepsilon$ &.,$\wedge$ & 4 &., 17 & $\varepsilon$ \\
\hline • & 0 & • & 0 &.,$\varepsilon$ & 0 \\
\hline . & 7 & • & 7 & & \\
\hline . & V & • & v & & \\
\hline . & $\wedge$ & • & $\wedge$ & & \\
\hline .17 & 9 & • & 9 & & \\
\hline.,$\varepsilon$ & 1. & & & & \\
\hline., 97 & المجموع & .19 & المجموع & & المجموع \\
\hline
\end{tabular}




\section{口معامل التمييز:}

يعتبر معامل تمييز المفردة أو قدرتها على التمييز دليلا على صدقها ، وتدل معامل التمييز

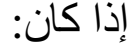

-معامل التمييز أقل من 0.19 تحذف الفقرة (تستبعد.)

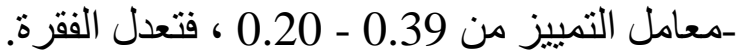
ـمعامل التمييز أكثر من 0.40 ، فتقبل الفقرة

و الجدول الآتي يوضح معاملات تمييز عباا رت مقياس الاختلاف وتقبل الاخر:

\begin{tabular}{|c|c|c|c|c|c|}
\hline \multicolumn{2}{|c|}{ الاختبار الثَالث } & \multicolumn{2}{|c|}{ الاختبار الثاني } & \multicolumn{2}{|c|}{ الاختبار الاول } \\
\hline معامل التمبيز & رقم المفردة & التمييز & رقم المفردة & معامل التمييز & رقم المفردة \\
\hline.,$\cdot 1$ & 1 &., 58 & 1 &.,$^{\text {ro }}$ & 1 \\
\hline ., IV & r &.,$Y^{\circ}$ & $r$ &.,${ }^{\prime} \wedge$ & r \\
\hline$\cdot$ & r & 0 & 3 &., $1 \mathrm{~V}$ & r \\
\hline . & $\varepsilon$ &., $1 V$ & 4 & Tr & $\varepsilon$ \\
\hline • & 0 &.${ }^{1 O}$ & 0 &.,$\cdot \wedge$ & 0 \\
\hline . & 7 & $\cdot$ & 7 & & \\
\hline . & v & • & v & & \\
\hline . & $\wedge$ & • & $\wedge$ & & \\
\hline rr, & 9 & • & 9 & & \\
\hline.,$\cdot 1$ & 1. & & & & \\
\hline קד & المتوسط &., 046 & المتوسط &., 182 & المتوسط \\
\hline
\end{tabular}

الخصائص الإحصائية للمقياس:

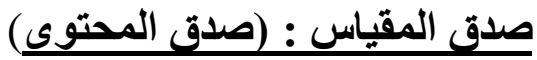

تم عرض المقياس في صورتنه المبلئية على مجمو عة من السادة المحكمين لإبداء ار ائهم واستجاباتهم في

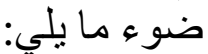
• مدى مناسبة المهار ات المختارة للمرحلة العمرية.

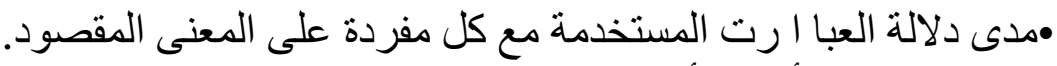

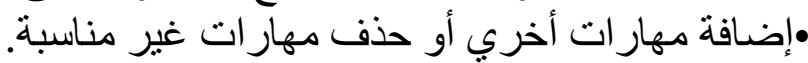

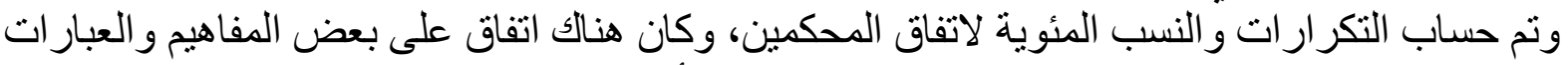

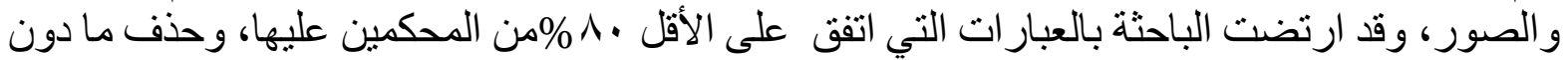


ذللك، وبذلك استبقت الباحثة على جميع مفردات المقياس، مع الأخذ في الاعتبار ملاحظات السادة

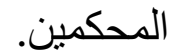
للتأكد من ثبات مقياس تقبل الطفل للاختلاف و التعايش مع الاخر تم حساب الثبات

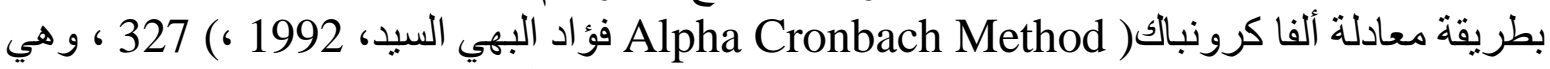
معادلة تستخدم في إيضاح المنطق العام للثبات، وكان (0.6) مما بدل علّي ان الاختبار متوسط الثبات

$$
\begin{aligned}
& \text { والاتساق الألبا: }
\end{aligned}
$$

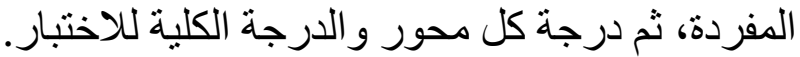

\begin{tabular}{|c|c|c|c|c|c|}
\hline \multicolumn{2}{|c|}{ الاختبار الثالث } & \multicolumn{2}{|c|}{ الاختبار الثاني } & \multicolumn{2}{|c|}{ الاختبار الاول } \\
\hline الارتباط & رقم المفردة & الارتباط & رقم المفردة & الارتباط معامل & رقم المفردة \\
\hline 0.548 & 1 & 0.195 & 1 & 0.417 & 1 \\
\hline 0.313 & $r$ & 0.467 & $r$ & 0.23 & $r$ \\
\hline 0.427 & r & 0.612 & r & 0.333 & r \\
\hline 0.317 & $\varepsilon$ & 0.47 & $\varepsilon$ & 0.492 & $\varepsilon$ \\
\hline 0.335 & 0 & 0.403 & 0 & 0.23 & 0 \\
\hline 0.27 & 7 & 0.34 & 7 & & \\
\hline 0.335 & V & 0.612 & V & & \\
\hline 0.541 & $\Lambda$ & 0.34 & $\Lambda$ & & \\
\hline 0.513 & 9 & 0.087 & 9 & & \\
\hline 0.485 & 1 . & & & & \\
\hline .0 .798 & الكلي & 0.781 & الكلي & 0.317 & الكلي \\
\hline
\end{tabular}

وصف لاجابات الاطفال علي الاسئلة الخاصة بمقاييس الاختلاف وتقبل الاخر :

$$
\text { الإجابات \% }
$$

\begin{tabular}{|c|c|c|c|}
\hline كلاهما & اسود & ضي & \\
\hline 12 & 28 & 60 & قبل \\
\hline 12 & 68 & 20 & بعد \\
\hline 4 & 24 & 72 & قبل \\
\hline 24 & 32 & 44 & بعد \\
\hline 8 & 32 & 60 & قبل \\
\hline 12 & 36 & 52 & بعد \\
\hline 16 & 20 & 64 & قبل \\
\hline 16 & 28 & 56 & بعد \\
\hline
\end{tabular}

أحد الطفلين فاز بجائزة المخترع الصغير ، تتوقع أيهج؟ ولماذا ؟ وتسأل : هل تعتقد أن إحدى اليدين أنظف من الأخرى أم أن كلا هما نظبف : هن حين تطلب منا المعلمة الانقسام لمجمو عات أختار أناو كوكو أو

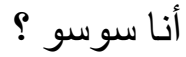

هل كلا الطفلين جميلين أم أن واحد منهم أجمل من الآخر؟

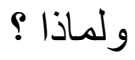




\begin{tabular}{|c|c|c|c|c|}
\hline 4 & 24 & 72 & |قبل & \multirow[t]{2}{*}{ أي الطفلتين تحب مشاركتها بالأكل؟ ولماذا؟ } \\
\hline 16 & 44 & 40 & بعد بع بع & \\
\hline ج & ب ب & آ & & الاختبار الثاني \\
\hline 32 & 60 & 8 & قبل & \multirow[t]{2}{*}{ حين ييكي ميمي لأنه فقد حقيبته ، ماذا ستفعل ؟ } \\
\hline ...... & 48 & 52 & 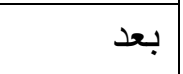 & \\
\hline 40 & 48 & 12 & قبل & \multirow{2}{*}{ حين يبكي سوسو لأنه فقد حقيبته ، ماذا ستفعل ؟ } \\
\hline … & 68 & 32 & بعد & \\
\hline 36 & 64 & $\cdots$ & قب قبل & \multirow{2}{*}{ تخفيل، أن لديكا صديقة اسمها ماري لا تتحدث العربية، ماذا } \\
\hline 36 & 64 & $\ldots$ & بعد & \\
\hline 44 & 48 & 8 & قبل & \multirow{2}{*}{ 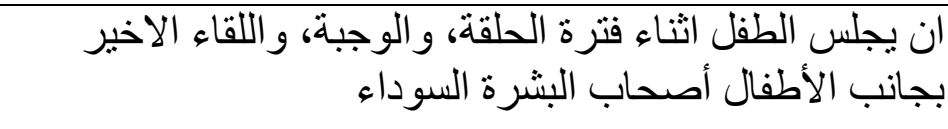 } \\
\hline 44 & 48 & 8 & بعد & \\
\hline 52 & 48 & $\ldots$ & 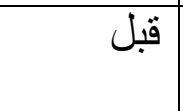 & \multirow{2}{*}{ فترة الملعب الخارجي وملعب من ذب الرملتياجات الخاصة في اللعب في } \\
\hline 64 & 8 & 28 & بعد & \\
\hline 48 & 52 & $\begin{array}{c}\ldots \\
\ldots\end{array}$ & ق قبل & \multirow[t]{2}{*}{ إذكون هذا الطفل صديقك بشكل غير لائق في الفصل، فإنني أتوقع أن } \\
\hline 40 & 60 & $\ldots$ & بعد & \\
\hline 20 & 80 & & ق قبل & \multirow[t]{2}{*}{ ما معنى كلمة " عامل نظافة " } \\
\hline$\cdots$ & 100 & $\ldots$ & بعد بعد | بعد & \\
\hline 80 & 20 & & 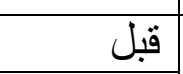 & \multirow[t]{2}{*}{ حين يرتدي طفل الزي الرجل المسيحي زي خاص به } \\
\hline ....... & 100 & $\ldots$ & بعد & \\
\hline 20 & 80 & & 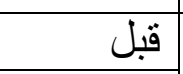 & \multirow[t]{2}{*}{ حين يرتدي طفله زميله للك صليب في رقبتها } \\
\hline & 100 & $\ldots$ & بعد & \\
\hline y & 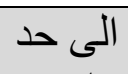 & نعم & & 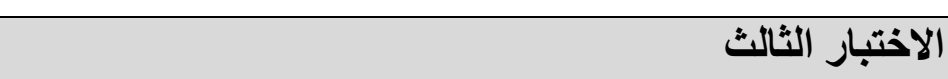 \\
\hline 48 & 48 & 4 & |قبله\% & \multirow{2}{*}{ هل يشارك الطفل العابه مع من يختلف عنه في لون البشرة؛ } \\
\hline 4 & 36 & 60 & بداد\% & \\
\hline 48 & 44 & 8 & |قبل\%\% & \multirow[t]{2}{*}{ هل يساعد الطفل المختلف عنه في الجنس في عمل ما؟ } \\
\hline 12 & 64 & 24 & بعد\% & \\
\hline 52 & 48 & $\ldots$ & 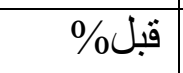 & \multirow[t]{2}{*}{ هل يتقبل الطفل حديث صديقه الذي لديه صعوبة في الكلام؟ } \\
\hline 36 & 64 & $\ldots$ & \% بعد\% & \\
\hline
\end{tabular}




\begin{tabular}{|c|c|c|c|c|}
\hline 52 & 48 & $\ldots \ldots$ & قبل\% & \multirow{2}{*}{ 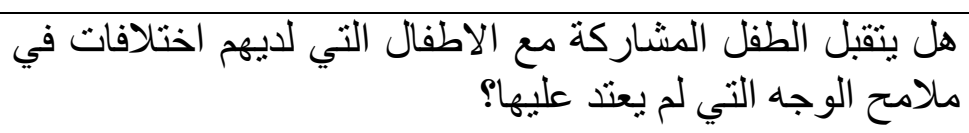 } \\
\hline 28 & 68 & 4 & بعد\% & \\
\hline 44 & 56 & ...... & قبل0\% & \multirow{2}{*}{ هل يتقبل الطفل التعايش مع اشخاص غير العائلة؟ } \\
\hline 12 & 84 & 4 & بعد\% & \\
\hline 48 & 52 & $\ldots$ & قبل\% & \multirow[t]{2}{*}{ هل يساعد الطفل صديقة المختلف عنه في عمل ما؟ } \\
\hline 20 & 76 & 4 & بعد\% & \\
\hline 44 & 56 & $\cdots$ & قبل0\% & \multirow{2}{*}{ هل يتقبل الطفل صديقه المختلف عنه في ديانته؟ } \\
\hline 32 & 64 & 4 & بعد\% & \\
\hline 68 & 32 & $\begin{array}{l}\cdots \\
\cdots\end{array}$ & قبل\% & \multirow[t]{2}{*}{ هركية - لغعب الطفل مع صدية - جسيقه ذوي الاحتياجات الخاصة (اعاقة } \\
\hline$\ldots \ldots$ & 16 & 84 & بعد\% & \\
\hline 24 & 60 & 16 & قبل0\% & \multirow[t]{2}{*}{ هل يلعبب الطفل مع صديقه البدين؟ } \\
\hline 4 & 8 & 88 & بعد\% & \\
\hline 76 & 20 & 4 & 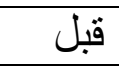 & \multirow{2}{*}{ هظهره؟ يشعر الطفل بالنقص عندما لا يتقبله الاخرين بسبب اختلاف } \\
\hline$\cdots \cdots$ & 76 & 24 & بعد & \\
\hline
\end{tabular}

التحقق من صحة الفروض دوض التوف ا ـتوجد فروق داله احصائيا عند مستوي 0.01 بين متوسطي درجات المجمو عه التجريبيه في القياسين

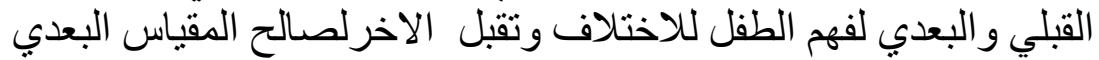

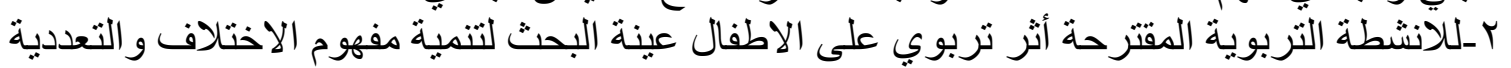
التقافية وقبول الاخر

نتائج مقياس الاختبار للمجموعة التجريبية ودلالاتها:

\begin{tabular}{|c|c|c|c|c|c|c|c|c|c|}
\hline مستوى الدلالة & "و قويلكوكسونة" & و واكبر & الوسبط & التباين & المعياري & المتوسط & ن & القياس & \\
\hline \multirow{2}{*}{$\begin{array}{c}\text { دالة عند) } \\
\text { (0.0001) }\end{array}$} & \multirow{2}{*}{-3.976} & $(1-4)$ & 2 & 0.807 & 0.898 & 2.16 & 25 & القبلي & \multirow{2}{*}{ الاختبار } \\
\hline & & $(2-5)$ & 4 & 0.643 & 0.802 & 3.68 & 25 & البعدي & \\
\hline \multirow{2}{*}{$\begin{array}{c}\text { دالة عند) } \\
\text { (0.0001) }\end{array}$} & \multirow{2}{*}{-4.325} & $(2-10)$ & 5 & 4.59 & 2.14 & 5.56 & 25 & القبلي & \multirow{2}{*}{ الاختبار } \\
\hline & & $(5-13)$ & 8 & 3.157 & 1.78 & 8.36 & 25 & البعدي & \\
\hline
\end{tabular}




\begin{tabular}{|c|c|c|c|c|c|c|c|c|c|}
\hline \multirow{2}{*}{$\begin{array}{c}\text { دالة عند } 2.0001) \\
\text { (0.001 }\end{array}$} & \multirow[b]{2}{*}{-4.387} & $(2-10)$ & 5 & 4.9 & 2.227 & 5.28 & 25 & القبلي & \multirow{2}{*}{ الاختبار } \\
\hline & & $(8-15)$ & 11 & 3.343 & 1.828 & 11.48 & 25 & البعدي & \\
\hline \multirow{2}{*}{$\begin{array}{c}\text { دالة عند) } \\
\text { (0.0001) }\end{array}$} & \multirow[b]{2}{*}{-4.385} & $(8-24)$ & 12 & 13.08 & 3.617 & 13 & 25 & القبلي & \multirow{2}{*}{ ككل المقياس } \\
\hline & & $(19-29$ & 24 & 5.5 & 2.347 & 23.5 & 25 & البعدي & \\
\hline
\end{tabular}

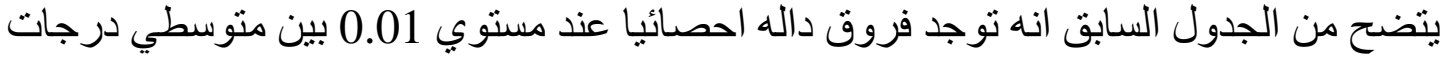

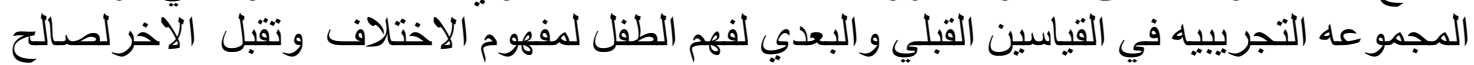

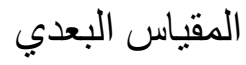

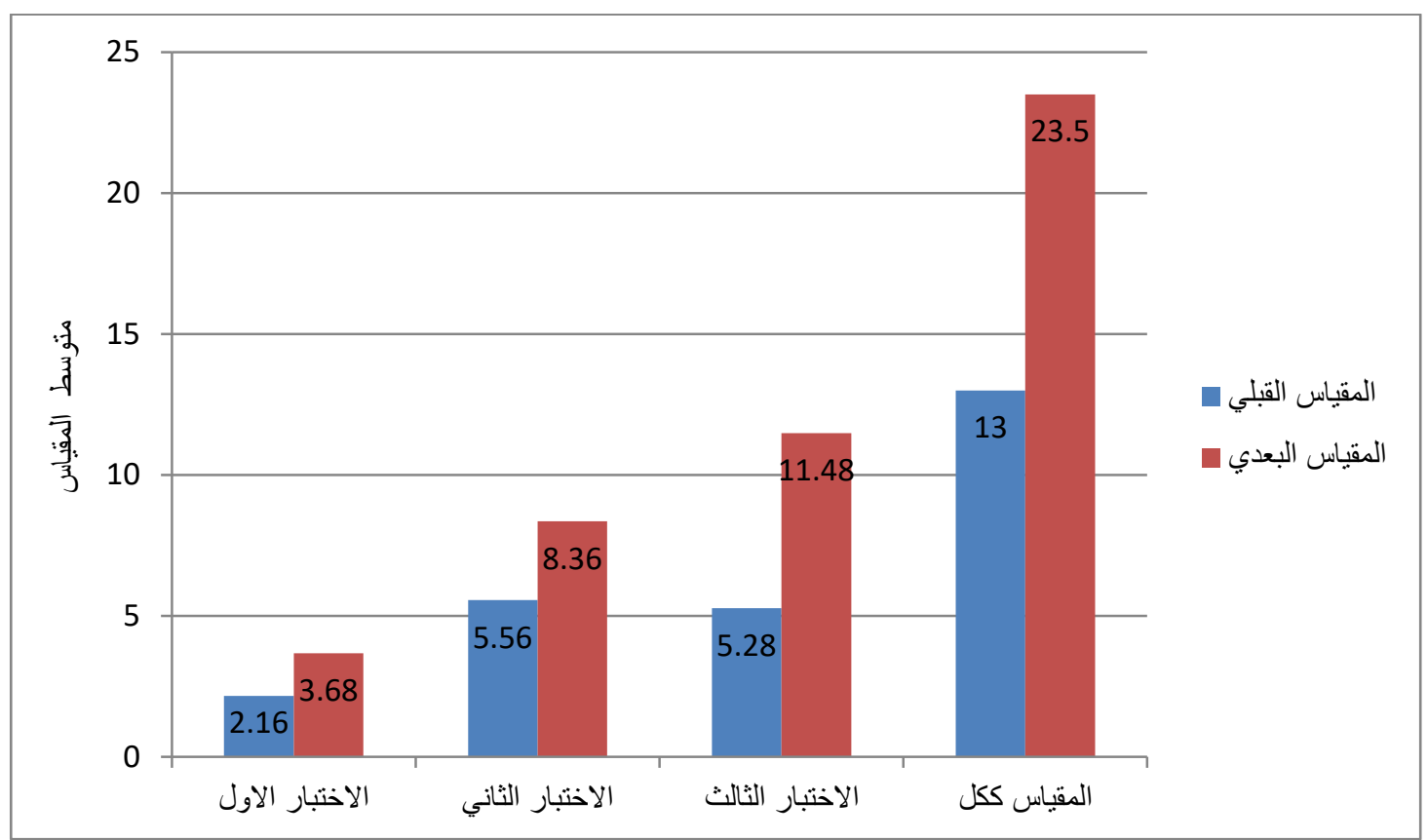

رسم بياني يوضح ناثير الانشطه علي تتمية مفهوم الاختلاف والتعددية الثقافية وقبول الاخر لدى الاطفال مناقثة وتفسير النتائج:

من استعر اض نتائج البحث ومناقثتها يمكن استخلاص ما توصل إليه البحث في الآتي: ا ـتوجد فروق دالة إحصائيا بين متوسطات درجات المجمو عة التجريبية في القياسين القبلي و البعدي

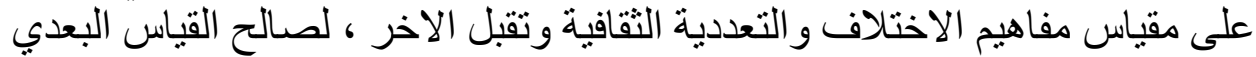

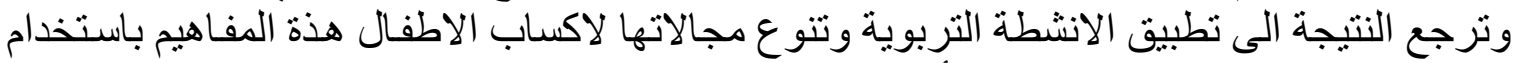

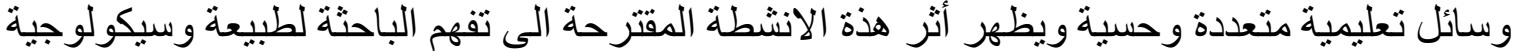

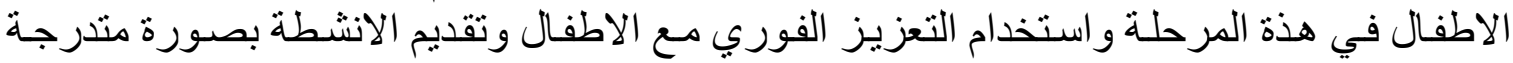
وحسية مرتبطة ببيئة الطفل 


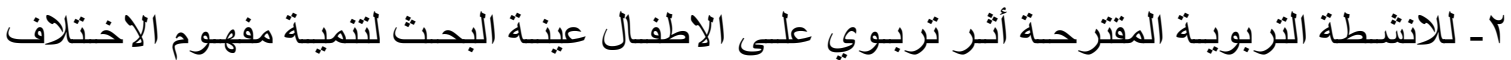

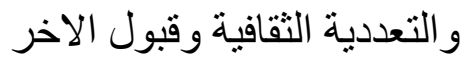

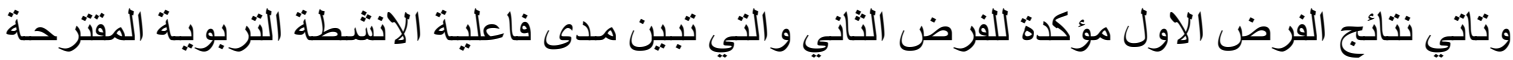

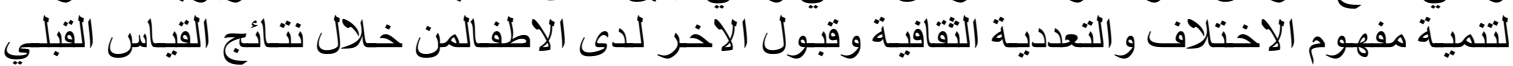

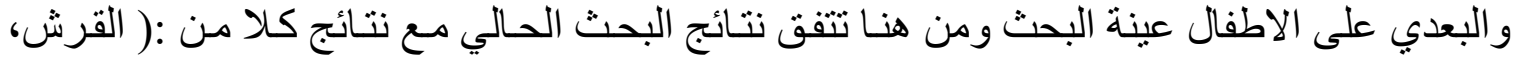

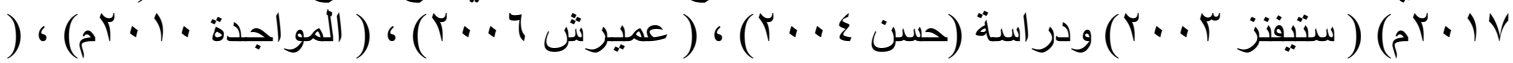
) ، Tangney $(Y . \vee$ Yabar\& Hess

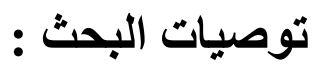

في ضوء نتائج البحث توصي الباحثة بمايلي : ا ـ ضرورة تضمين بر امج الطفولة المبكرة لمفاهيم احتر ام وتقبل التعددية التقافية و اختلاف الاخر r- عمل دورات تثقيفية لأولياء الأمور لتقديم بعض الأنشطة التي تساعد الطفل علي فهم شخصيته و تقبل الاخر r- الوعي بأهمية مفهوم تقبل الاخر وتنميته للطفل في مرحلة الطفولة المبكرة

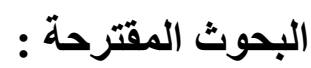
في ضوء ما تقدم يمكن للباحثة أن تقدم بعض النقاط التي يمكن أن تصلح امتداداً للبحث الحالي: ا ـ فاعلية مسرح العر ائس في تنمية مفاهيم التعايش السلمي للأطفال r- فاعلية الدر اما الإبداعية في اكساب طفل الروضة بعض المفاهيم الاجتماعية بـ فاعلية المشاركة الأسرية و المجتمعية في اكساب طفل الروضة مفهوم تقبل الاخر عـ - ـدر اسة مقارنة بين بعض استر اتيجيات التعلم على اكساب الاطفال مفهوم التعددية الثقافية وقبول الاختلاف 


\section{أولا : المراجع العربية}

ا ـ أحمد إسماعيل ححم)( • • r r):توجهات الفلسفة التربوية لمجتمع المعرفة و معوقات تحقيقها بالمؤسسات التعليمية من وجهة نظر الطلاب المعلمين، المؤتمر الدولي الخامس للمركز العربي للتعليم و التنمية، مستقبل اصلاح التعليم العربي لمجتمع المعرفة ، المركز العربي للتعليم و التنمية، القاهرة، جمهورية مصر العربية.

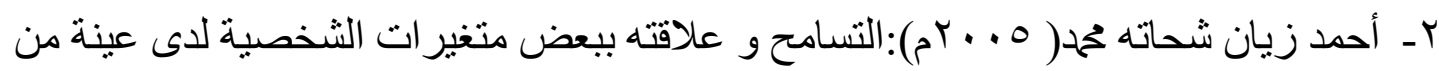
طلبة المرحلتين الثانوية و الجامعية، رسالة دكتور اه غير منشورة، جامعة القاهرة، جمهورية مصر العربية، معهد الدر اسات التربوية. r- الجعفري ، هناء هاثتم (9 ؟ ( هـ) :التربية بالقصة في الاسلام وتطبيقها في رياض الاطفال تصوير مسرح. عـ الكيلاني شمس الدين ( • ( • rم):الحوار ثقافة التسامح، بغداد، بيت الحكمة للنشر و التوزيع.

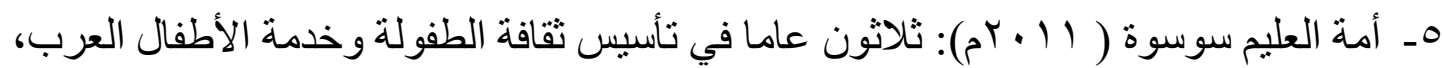
الجمعية الكويتية لتقدم الطفولة العربية، الكويت، ص هـو.9.

ــ اير ام سر اج - بلا تشفورد برسيلاكلارك (0 ץ) : الاطفال في السنوات المبكرة وكيف ندعهم ( الهوية ـ التنوع - اللغة ) مجمو عة النيل العربية ، طا ، مصر V- بكر المواجدة (• ( • r م ): دور كتب الثقافة الإسلامية المدرسية في حوار الحضار ات من خلال نشر ثقافة الحوار و التسامح مع الاخر، الأردن، مجلة جامعة النجاح للأبحاث، العلوم الإنسانية،

ᄉـ بهارد ،سعدية محمد علي (9VV) (م):علم النفس النمو ،الكويت دار البحوث العلمية. 9- تيريز ادي فازيو( • ( • rم)، احتر ام الذات و معرفة الاخر دليل المعلم، سيدني، استر اليا، المفوضية الاستر الية لحقوق الانسان و الجمعية الاستر الية للغات الجاليات العرقية.

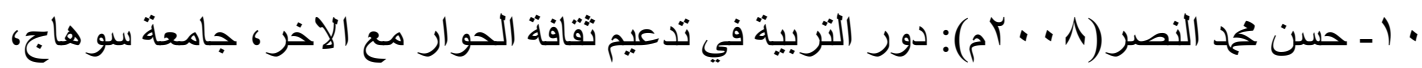
المؤتمر العلمي العربي الثالث، التعليم و قضايا المجتمع المعاصر ، المجلد الثاني، جمعية الثقافة

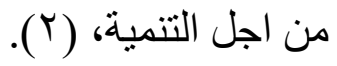
1 ا ـ حجيت جوزيف و اخرون (0 1 • ( ) : دروس للحياة التربية لمناهضة العنصرية من رياض الاطفال حتي الثانوية 


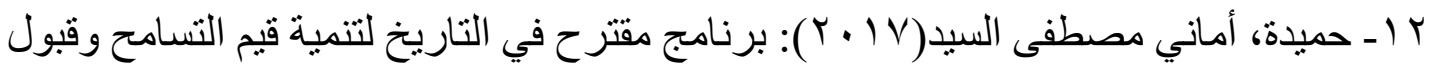
الآخرلدى تلاميذ المرحلة الإبتدائية ،المؤتمر الدولي للجمعية التربوية للار اسات الاجتماعية: الجمعية التربوية لدر اسات الاجتماعية القاهرة

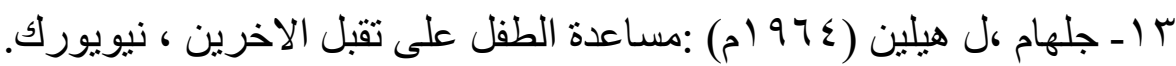

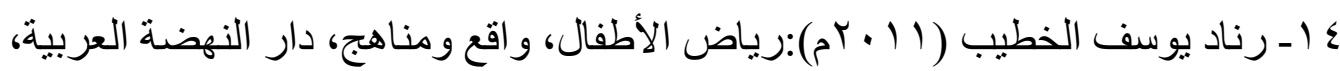

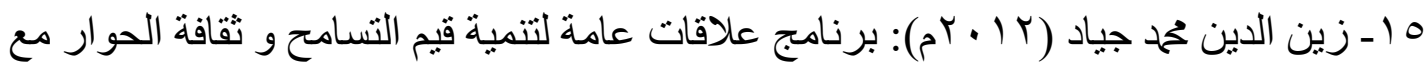

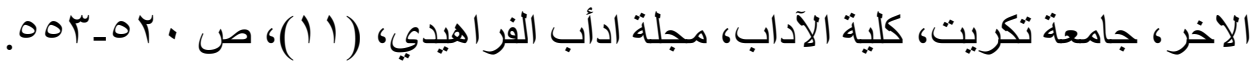

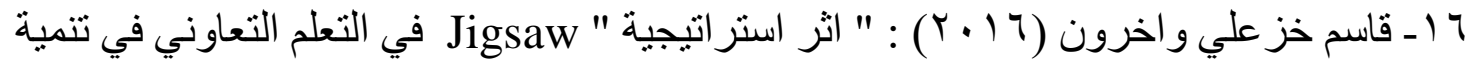
التسامح الاجتماعي لدي عينة من طلبة الصف العاثر الاساسي في مدينة أريد " ، المجلة

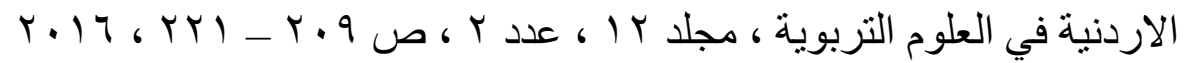

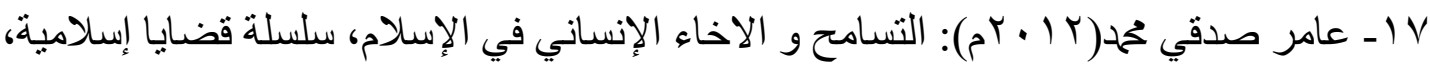
العدد r.r، القاهرة، جمهورية مصر العربية، المجلس الأعلى للثئون الإسلامية، وزارة

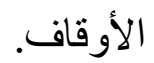

1 ا ـ عبد الله إبر اهيم( ع . . ץم): المطابقة و الاختلاف، المؤسسة العربية للار اسات و النشر،

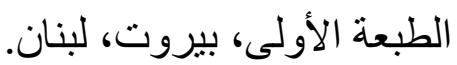

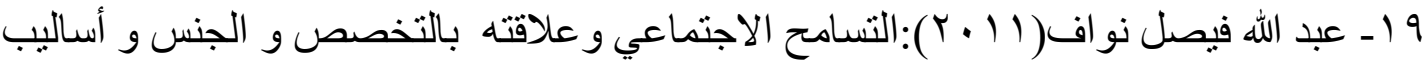

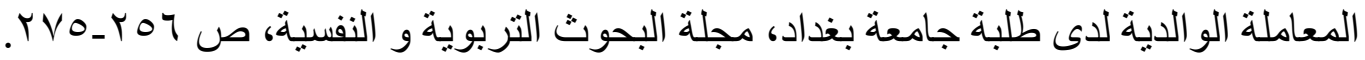

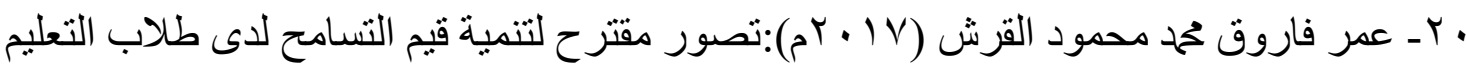
الثانوي الصناعي، مجلة كلية التربية، جامعة الازهر ، العدد بل ا، الجزء الأول، جامعة حلوان، جمهورية مصر العربية.

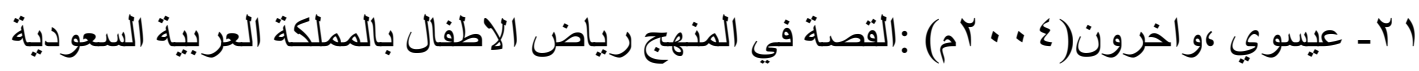

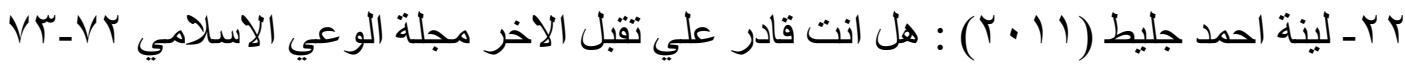

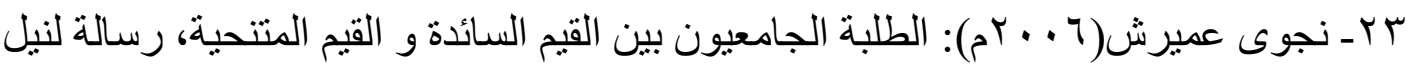
شهادة الماجستير، جامعة قسنطينة.

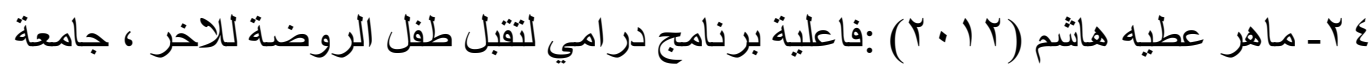

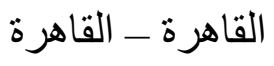




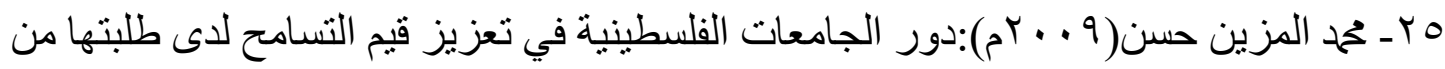

$$
\begin{aligned}
& \text { وجهة نظر هم، رسالة ماجستير غير منشورة، الجامعة الإسلامية، غزة، كلية التربية. }
\end{aligned}
$$

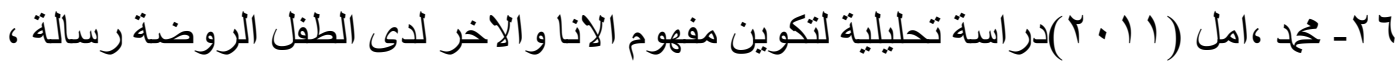

$$
\begin{aligned}
& \text { رسالة ماجستير غير منشورة، جامعة عين شمس }
\end{aligned}
$$

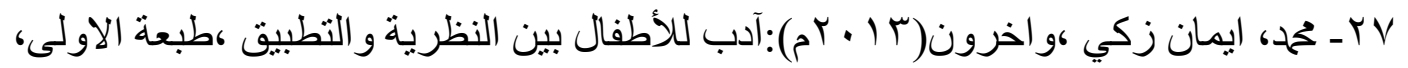
الرياض :الرشد.

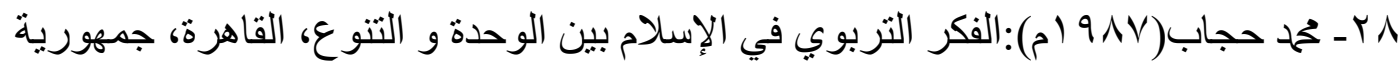
مصر العربية، المؤتمر العالمي الخاص للتربية الإسلامية، المركز العام لجمعيات الثباب

$$
\text { المسلمين العالمية، الجزء الثاني، ص } 9 \text { ب7 ـ ـ } 70 .
$$

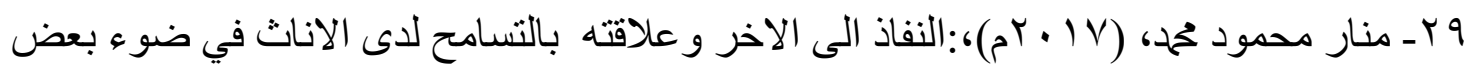
المتغير ات الديموجر افية، كلية البنات، جامعة عين شمس، العدد (1 ( )، لجز

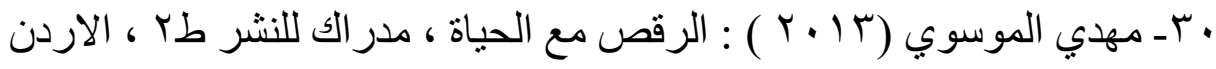
اس ـ ميرفت عبد الحمبد حسن(ع . . بم:تقبل الاخرين في التربية الإسلامية، رسالة ماجستير غير منشورة، الأردن، اليرموك، كلية الثريعة.

\section{ثانيا : المراجع الأجنبية}

33-Christy,s,ellen,h.(2010):dramatic play ase context for childrenes investigation of size and scale . ecrp $: \mathrm{v}(10), \mathrm{n}(2)$

34-Marie,e (2013):how dran at ic play can enhance learning .retrie ved form :Www.early childhood.com.

35-Mary,b,sue,b.(2008): At the zoo: kindergartners reinvent a dram attic play area. Ecrp:v(10)n(2)

36-Caliskan,h.\&saglam,h(2012):astudy on the development of the tendency to tolerance scale and analysis of the tendencies of primary school students to tolerance certain variables theory and practice v12n,2p,p14401446,apr2012 
37-Tangney, J. (2005): Forgiving The self: Conceptual Issues and empirical Findings. Ed. Handbook of Forgiveness, George Mason Universty.

38-Rodden, J. (2001): Education for Tolerance, education for national identity. The unusable German past. Review of Contemporary German affairs. 9, (1),5678.

39-Stephens, F. (2003): An Examination o the effectiveness of a program on cultural tolerance and diversity for teacher education candidates. DAI-A 63/10. 40-Yabara,Y. \&Hess,U. (2007): Display empathy and perception pf out group members.New Zealnd journal of psychology, vol.36,No.1 